\title{
miR-128 exerts pro-apoptotic effect in a p53 transcription-dependent and -independent manner via PUMA-Bak axis
}

\author{
YK Adlakha ${ }^{1}$ and N Saini ${ }^{1}$
}

p53 has attracted tremendous attention due to its master role in tumor development. Activation of p53 in tumor cells has been the prime focus for cancer drug discovery. Recent studies have shown that few miRNAs can regulate p53 activity directly or indirectly. We herein demonstrate that miR-128 positively regulates p53 activity. Our data suggest that miR-128 inhibits SIRT1 expression directly through a miR-128-binding site within the $3^{\prime}$ UTR of SIRT1. miR-128 inhibition of SIRT1 led to an increase in acetylated p53 and its transcriptional targets. miR-128 decreased phospho-Akt and phospho-FOXO3A, increased acetylated FOXO3A and promoted FOXO3A translocation to the nucleus. We further demonstrated that miR-128 augments the antitumor effect of compounds that target the p53 pathway. Furthermore, miR-128 induces apoptosis in wild (WT) p53 as well as in mutant p53-expressing cells in a p53-dependent and -independent manner via induction of PUMA. Pretreatment with PUMA and Bak siRNAs abolished miR-128-induced apoptosis in HCT116 p53 + I+ and HCT116 p53 - / - cells. Taken together, we present the first evidence of miR-128 to be a new component joining the p53 network. This study emphasizes that miR-128 is a novel mitochondria-targeted miRNA that can be further evaluated as a chemotherapeutic agent for human cancers as it induces apoptosis irrespective of $\mathrm{p} 53$ status.

Cell Death and Disease (2013) 4, e542; doi:10.1038/cddis.2013.46; published online 14 March 2013

Subject Category: Cancer

p53, the central factor of a complex molecular network, has a crucial role in maintaining genomic stability and tumor suppression. Under normal, unstressed conditions, rapid proteasomal degradation of p53 keep a check on its half-life. During stress, such as genotoxic damage or hypoxia, posttranslational modification leads to p53 stabilization; the accumulated p53 transactivates the expression of a number of target genes that collectively contribute to p53-dependent cellular response. The biological outcomes of p53 activity include apoptosis, inhibition of cell cycle progression, senescence, differentiation and accelerated DNA repair. ${ }^{1}$ It is estimated that $80 \%$ of tumors have dysfunctional p53 signaling and TP53 gene encoding the p53 protein is mutated in $\sim 50 \%$ of all human cancers. To maintain its proper function, $\mathrm{p} 53$ is tightly regulated by a wide variety of regulators in cells. ${ }^{2}$ New levels of p53 regulation by miRNA have been identified as it can be regulated directly by miR- $504^{3}$ and miR$125 b^{4}$ and indirectly by miR-34a, ${ }^{5}$ miR $-122^{6}$ and miR-29. ${ }^{7}$

MiRNAs are single stranded, $\sim 22$ nucleotides (nt) in length and they modulate gene expression at post-transcriptional level in a sequence-specific manner. ${ }^{8}$ Their profound impact on several pathophysiologic processes, including development, differentiation, proliferation, apoptosis and metabolism, makes them the focus of interest for therapeutic intervention. ${ }^{9-11}$
Recent studies have correlated altered expression of specific miRNA genes with severe disease phenotypes like cancer. ${ }^{12}$ miRNAs can function as either tumor suppressor ${ }^{13}$ or oncogene ${ }^{14}$ depending upon their downregulation or increased expression. Downregulation of $\mathrm{miR}-128$ has been reported in several cancer types, for example, neuroblastoma,${ }^{15}$ glioblastoma, ${ }^{16}$ prostate cancer, ${ }^{17}$ lung cancer ${ }^{18}$ and MLL-AF4 acute lymphocytic leukemia. ${ }^{19}$ The region 3p22.3 that transcribes miR-128-2 is lost in neuroblastoma as well as lung carcinoma. ${ }^{15,18}$ Previous studies, ${ }^{16}$ including ours, ${ }^{20}$ showed the antiproliferative/pro-apoptotic potential of miR-128. All these studies point towards the tumor suppressive role of miR-128, but till date no studies have been performed to investigate its mechanism behind tumor suppression. A previous study from our laboratory ${ }^{20}$ also pointed towards upregulation of p53 after miR-128 overexpression. As understanding the mechanism by which p53 functions in the execution of cell death pathways is of considerable importance in cancer biology, we next set out to explore p53 function in miR-128-induced apoptosis.

Herein, we demonstrate that $\mathrm{miR}-128$ negatively regulates SIRT1, a $\mathrm{NAD}^{+}$-dependent deacetylase, that regulates apoptosis in response to oxidative and genotoxic stress. Results herein also suggest that miR-128 induces cell death in

\footnotetext{
${ }^{1}$ Functional Genomics Unit, Institute of Genomics and Integrative Biology (IGIB), Council of Scientific and Industrial Research (CSIR), Delhi, India

*Corresponding author: N Saini, Functional Genomics Unit, Institute of Genomics and Integrative Biology (IGIB), Council of Scientific and Industrial Research (CSIR), Mall Road, Delhi 110007, India. Tel: + 9111 27666156; Fax: + 9111 27667471; E-mail: nsaini@igib.in

Keywords: microRNA (miRNA); miR-128; apoptosis; p53; SIRT1; FOXO3A

Abbreviations: SIRT1, Sirtuin (Silent mating type information regulation 2, homolog) 1; MOMP, mitochondrial outer membrane permeabilization; PUMA, p53upregulated modulator of apoptosis; FOXO3A, Forkhead Box O3A; IGFBP5, Insulin-like growth factor-binding protein 5; Col5A1, Collagen, type V, alpha 1; TGF $\beta 1$, transforming growth factor beta-1; $\mathrm{RXR} \alpha$, Retinoid $\mathrm{X}$ receptor alpha

Received 10.8.12; revised 26.12.12; accepted 16.1.13; Edited by E Candi
} 
a p53-dependent and -independent manner through PUMABak axis via p53 and FOXO3A.

\section{Results}

Gene expression, cell death and cell cycle are the major functions of miR-128, as revealed by IPA. Previous studies in our laboratory have demonstrated that miR-128 upregulates p53 and induces apoptosis in HEK293T cells. ${ }^{20}$ To understand the molecular mechanism by which miR-128 induces apoptosis, genome-wide gene expression profiling of miR-128-transfected and untransfected HEK293T cells was performed using Illumina human WG-6 v.3.0 beadchip (Illumina, San Diego, CA, USA). We first confirmed five-fold increase in miR-128 expression after transfection of miR-128 in HEK293T cells by northern blotting (Figure 1a), and then performed microarray, as shown in schema (Supplementary Figure S1). Data analysis using Bead Studio module of Illumina identified 182 differentially expressed genes (51 upregulated and 131 downregulated, Supplementary Figure S1). List of differentially expressed genes is given in Supplementary Table S1.

Analysis of the dataset with Ingenuity Pathway Analysis (IPA Version 7.5; IPA Tool; IngenuitySystems, Redwood City, CA, USA; http://www.ingenuity.com) software showed top three associated networks as cancer, cellular growth and proliferation, gene expression; hematological system development and function, hematological disease; cell cycle, cancer, DNA replication, recombination and repair (Table 1(a), Supplementary Table S2). Table 1(b) and (c) a

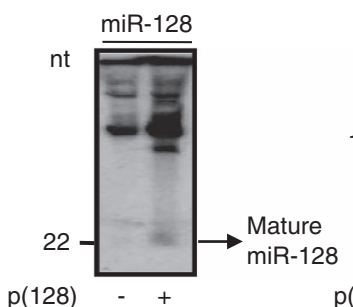

b

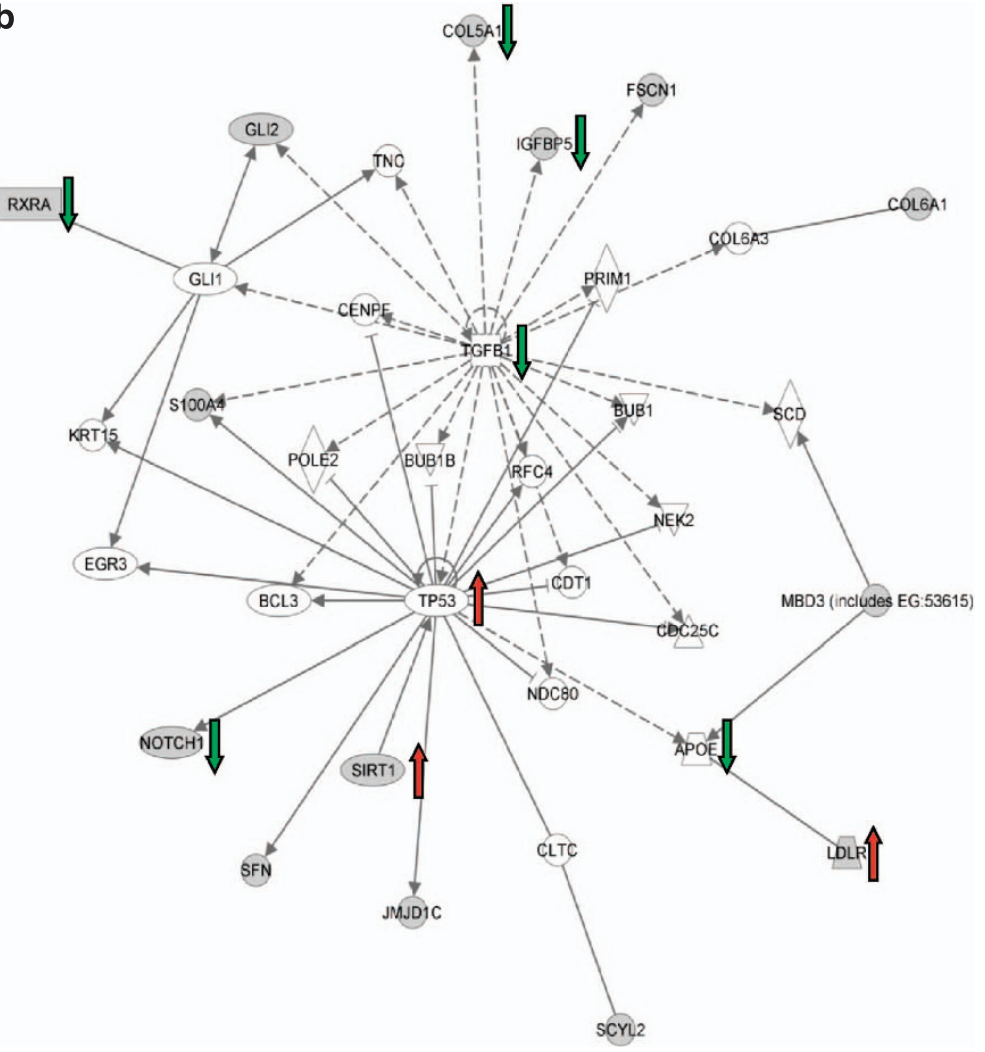

C
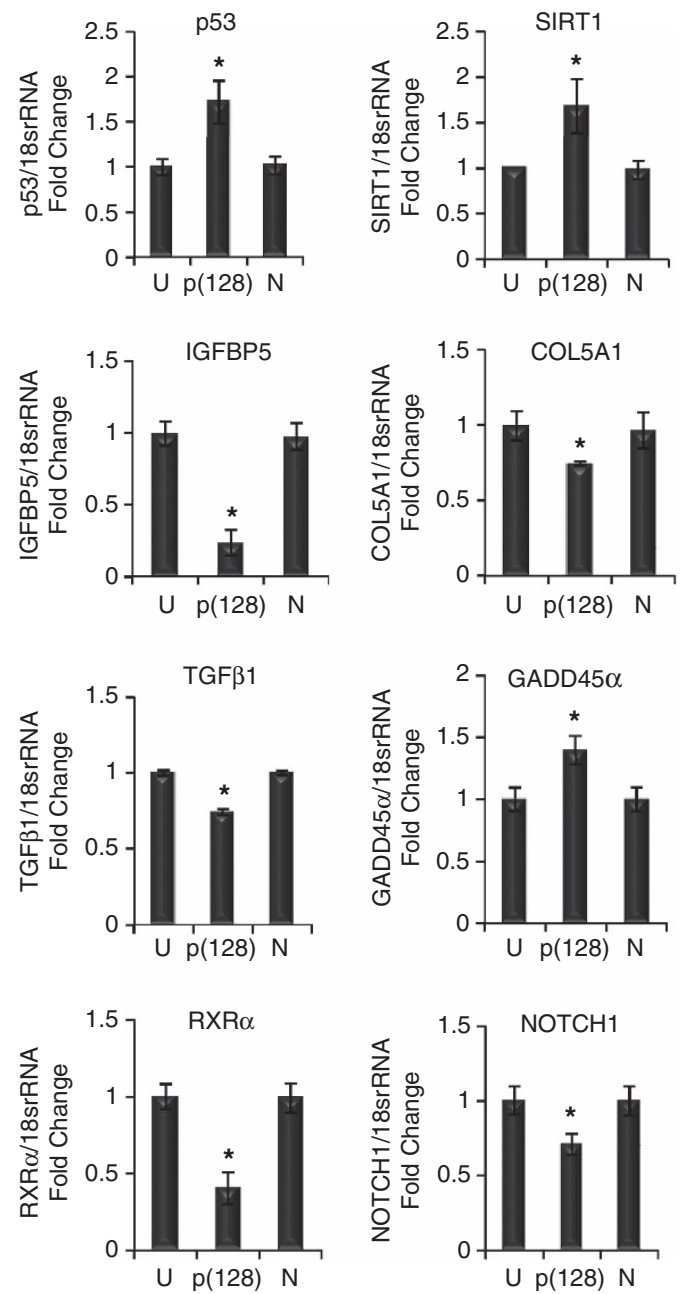

Figure 1 Network analysis shows p53 as the major hub molecule regulated by miR-128. (a) Northern blot analysis of total RNA extracted from untransfected HEK293T cells and HEK293T cells transfected with $4 \mu \mathrm{g} \mathrm{p}(128)$. Hybridization to the U6 small nuclear RNA is shown as a loading control. Graph shows fold changes in miR-128 expression after $24 \mathrm{~h}$ of transfection. $n=3 \pm$ S.D.; ${ }^{*} P<0.05$ versus control. (b) Network as generated by IPA. The significant functions comprising this network are cell cycle, cancer, DNA replication, recombination and repair. A solid line represents the direct interaction among the different gene products and a dotted line depicts indirect interaction. The genes that are dark shaded represent the genes from our dataset and were determined to be significant by statistical analysis. The genes with red arrow are upregulated and those with green are downregulated. (c) Real-time PCR analysis of p53, SIRT1, GADD45 $\alpha$, RXR $\alpha$, IGFBP5, COL5A1, NOTCH1 and TGF $\beta 1$ mRNAs in miR-128-transfected HEK293T cells. 18s rRNA was used for the normalization. $n=3 \pm$ S.D.; ${ }^{*} P<0.05$. $U=$ untransfected, $p(128)=$ HEK293T cells transfected with $4 \mu \mathrm{g} p(128), N=$ negative control 
Table 1 Gene expression profiling revealed top three networks, top three molecular and cellular functions and top three biological functions as generated by Ingenuity Pathways Analysis (IPA) along with their representative scores and respective $P$-value. (a): top three networks. (b): top three molecular and cellular function. (c): top three bio functions

\section{(a)}

\begin{tabular}{llc} 
ID & Associated network functions & Score \\
\hline 1 & $\begin{array}{l}\text { Cancer, cellular growth and } \\
\text { proliferation, gene expression } \\
\text { Hematological system development } \\
\text { and function, tissue morphology, }\end{array}$ & 21 \\
hematological disease \\
Cell cycle, cancer, DNA replication, \\
recombination and repair
\end{tabular}

(b)

\begin{tabular}{|c|c|c|}
\hline$P$-value & $\begin{array}{l}\text { Associated molecular and } \\
\text { cellular function }\end{array}$ & $\begin{array}{l}\text { Focus } \\
\text { molecule }\end{array}$ \\
\hline $6.38 \mathrm{E}-09$ to $4.66 \mathrm{E}-02$ & $\begin{array}{l}\text { Cellular growth and } \\
\text { proliferation }\end{array}$ & 43 \\
\hline $\begin{array}{l}6.98 \mathrm{E}-07 \text { to } 3.83 \mathrm{E}-02 \\
1.46 \mathrm{E}-04 \text { to } 4.57 \mathrm{E}-02\end{array}$ & $\begin{array}{l}\text { Gene expression } \\
\text { Cell death }\end{array}$ & $\begin{array}{l}31 \\
22\end{array}$ \\
\hline \multicolumn{3}{|l|}{ (c) } \\
\hline$P$-value & $\begin{array}{l}\text { Associated biological } \\
\text { function }\end{array}$ & $\begin{array}{l}\text { Focus } \\
\text { molecule }\end{array}$ \\
\hline $\begin{array}{l}3.02 \mathrm{E}-05 \text { to } 4.79 \mathrm{E}-02 \\
1.71 \mathrm{E}-04 \text { to } 4.40 \mathrm{E}-02 \\
4.88 \mathrm{E}-04 \text { to } 4.57 \mathrm{E}-02\end{array}$ & $\begin{array}{l}\text { Cancer } \\
\text { Neurological disease } \\
\text { Reproductive system } \\
\text { disease }\end{array}$ & $\begin{array}{l}49 \\
11 \\
16\end{array}$ \\
\hline
\end{tabular}

shows the top three most enriched molecular and cellular functions and top three biological functions as revealed by the IPA Tool. Our previous data showed that overexpression of miR-128 upregulates p53, p-p53 and Bak proteins and induces mitochondria-mediated apoptosis in HEK293T cells. ${ }^{20}$ As p53 turned out to be a key gene in one of the top networks also (Figure 1b), we hypothesized that p53 might have a key role in miR-128-induced apoptosis. Subset of genes of the p53 network were validated by qRT PCR. As shown in Figure 1c, transfection of miR-128 significantly increased the mRNA levels of p53, SIRT1 and GADD $45 \alpha$, whereas it decreased the mRNA levels of IGFBP5, COL5A1, TGF $\beta 1, \mathrm{RXR} \alpha$ and NOTCH1 in HEK293T cells (Figure 1c). Increased p53 and SIRT1 mRNA levels were also found in $\mathrm{NCl}-\mathrm{H} 460$ cells (Supplementary Figures S2a and b).

SIRT1 is a direct target of miR-128. In silico analyses predicted highly conserved binding site (at positions $849-855 \mathrm{nt}$ ) in the $3^{\prime}$ UTR of SIRT1, one of the genes of the validated network (Figure 2a). ${ }^{21,22}$ To validate that miR-128 targets SIRT1, the expression of miR-128 and SIRT1 was determined in HEK293T cells after miR-128 overexpression. Significant decrease in SIRT1 expression and increase in miR-128 expression was observed in a dose-dependent manner (Figures $2 b$ and $c$ ), and the effect of miR-128 was reversed by anti-miR-128 treatment (Figures $2 \mathrm{~b}$ and $\mathrm{c}$ ). Similar results were observed in $\mathrm{NCl}-\mathrm{H} 460$ cells (Supplementary Figures S2c and d). To assess whether SIRT1 is a direct target of miR-128, we performed dual luciferase assay in HEK293T and NCl-H460 cells with SIRT1 reporter construct in the absence or presence of miR-128 or in combination with anti-miR-128 as described in Materials and Methods. miR-128 decreased luciferase activity by $35 \%$ and inhibition of miR-128 by antimiR-128 at 30 and $60 \mathrm{nM}$ concentration increased the luciferase activity by 50 and $75 \%$ in HEK293T (Figure 2d) and $\mathrm{NCl}-\mathrm{H} 460$ cells (Supplementary Figure S2e). To ascertain that miR-128 shows effects via a specific target sequence localized in the SIRT1 $3^{\prime}$ UTR, we generated a reporter construct in which the sequence complementary to the seed region (2-8nt) of miR-128 in the 3'UTR of SIRT1 was deleted (shown by asterisks in Figure $2 \mathrm{a}$ ). The resulting mutant construct (mutant SIRT1 3'UTR) and wild-type SIRT1 3'UTR (WT SIRT1 3'UTR) were cotransfected with negative control or miR-128 in HEK293T and MCF-7 cells and luciferase assay was done. In contrast to wild-type SIRT1 $3^{\prime} U T R$, there was no change in the luciferase activity when mutant SIRT1 3'UTR was cotransfected with negative control or miR-128 (Figure 2e and Supplementary Figure S3).

It is known that during apoptosis, SIRT1 localizes to cytoplasm from the nucleus. ${ }^{23}$ Hence, we further set out to check the subcellular localization of SIRT1 by immunofluorescence. Our results demonstrated that both untransfected and negative control transfected cells showed nuclear localization of SIRT1, whereas SIRT1 localizes to cytoplasm after miR-128 overexpression (Figure 2f). The quantitative analysis of the SIRT1 immunofluorescence intensity in nucleus revealed that the mean intensity was decreased by two-fold after miR-128 over expression. Taken together, these data strongly suggest that miR-128 decreases SIRT1 mRNA translation by binding to the response element in the SIRT1 $3^{\prime}$ UTR and induces nucleocytoplasmic shuttling of SIRT1.

miR-128 positively regulates p53 and its transcriptional targets. As SIRT1 is a potential target of miR-128 (Figures $2 \mathrm{~d}$ and $\mathrm{e}$ ) and it can also regulate $\mathrm{p53}$ by deacetylation, ${ }^{24}$ it was anticipated that by downregulating SIRT1, miR-128 should be able to enhance acetylation of p53. Once acetylated, p53 is responsible for the transcriptional activation of a series of proteins involved in cell cycle control, apoptosis and senescence. ${ }^{25,26}$ To test this notion, we checked p53 transcriptional activity using a reporter assay and assessed the effect of transfection of miR-128 on the levels of p53 and its transcriptional targets that mediate cell cycle arrest (p21) and apoptosis (PUMA, NOXA) using western blotting. As expected, miR-128 overexpression increased p53 transcriptional activity (Figure 3a), decreased SIRT1 and increased total p53, acetylated p53 (at lysine382) and its target PUMA in HEK293T and HCT116 p53 $+/+$ cells (Figures $3 \mathrm{~b}$ and $\mathrm{c}$ ). However, there was no change in levels of p53 and acetylated p53 after overexpresion of miR-128 in p53 null HCT116 - / - cells despite decreased SIRT1 and increased PUMA expression (Figure 3d). In addition, miR-128 overexpression also induced apoptosis in both HCT116 p53+/+ as well as HCT116 p53 - / - cells (Supplementary Figures S4a and b). Overexpression of $\mathrm{miR}-128$ also induced the expression of p21 and NOXA in HEK293T cells (Figure 3e).

p53 transcriptional activity can only be executed if its interaction with its inhibitor MDM2 (murine double minute 2) is abolished, and AKT-mediated phosphorylation of MDM2 has been known to activate MDM2. ${ }^{27}$ Hence, the effect of miR-128 


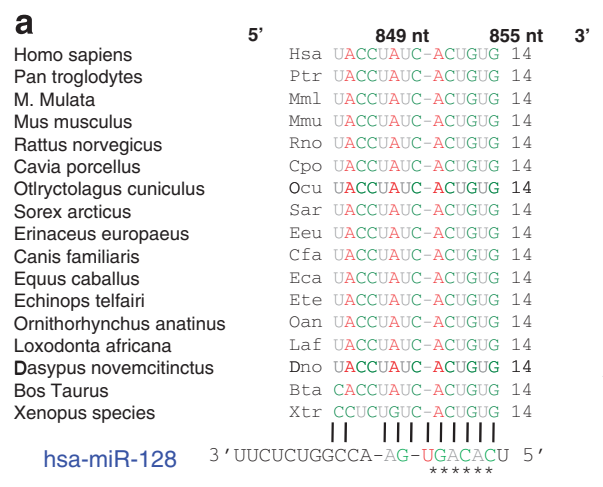

b

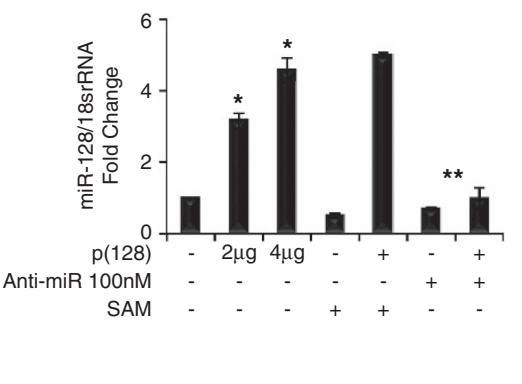

C

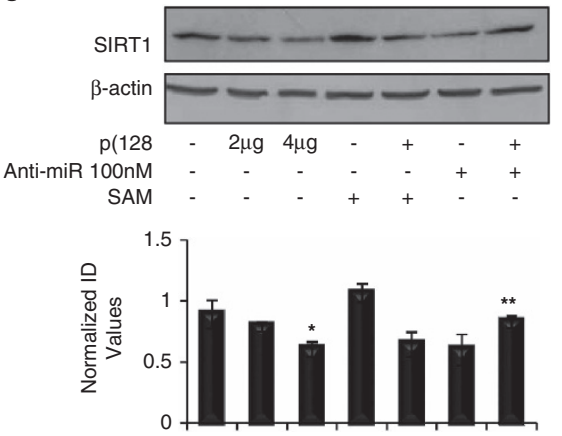

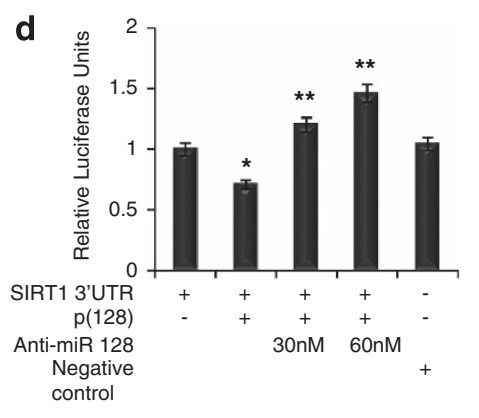

e

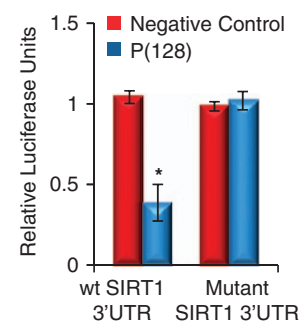

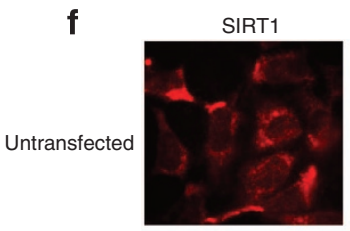
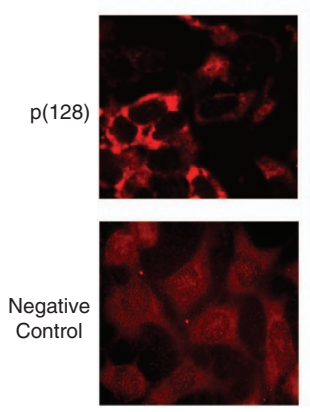
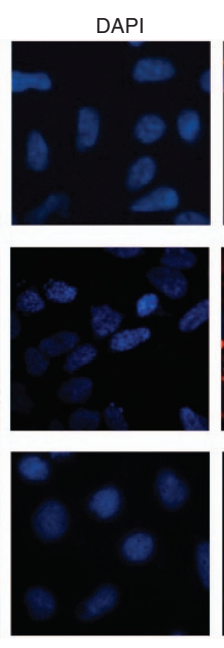
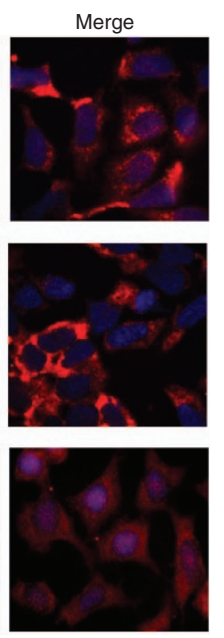

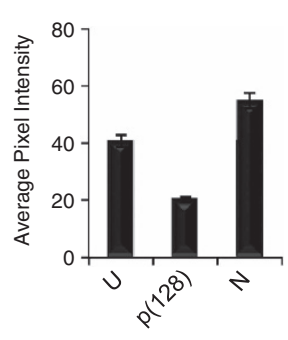

Figure 2 SIRT1 is a direct target of miR-128. (a) The binding site of miR-128 in the $3^{\prime} U T R$ of SIRT1 is highly conserved among different species as predicted by TargetScan 5.2. For mutation experiment, the miR-128 binding site has been deleted from SIRT1 3'UTR as shown by asterisks. (b) Taqman assay for mature miR-128 (c) Western blot analysis for SIRT1 expression in HEK293T cells transfected with $p(128)$ and/or with anti-miR-128 in a dose-dependent manner. SAM represents the

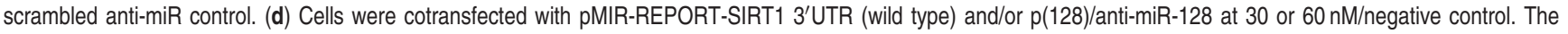
luciferase activity relative to pMIR-REPORT (intact) was plotted. (e) The reporter constructs including wild-type or mutant SIRT1 $3^{\prime}$ UTR was cotransfected with either miR-128 or negative control. The luciferase activity relative to negative control was plotted. $n=3 \pm$ S.D.; ${ }^{*} P<0.05,{ }^{* \star} P<0.001$ for all the panels. (f) Immunofluorescence showed that SIRT1 translocated to cytoplasm from nucleus after overexpression of miR-128 in HEK293T cells. Nuclei were counterstained with the DNA-binding dye DAPI (49,6-diamidino2-phenylindole; blue). Representative of three independent experiments is shown here $(n=3)$. Mean fluorescence intensities of nuclear regions of 10 cells in each condition (untreated and treated) were quantitated using image analysis as described under 'Materials and Methods'

on the phosphorylation of AKT and MDM2 was studied in HEK293T cells. As shown in Figures $3 f$ and $g$, miR-128 overexpression led to significant reduction of phospho-AKT and phospho-MDM2 levels. It is likely that the increased p53 transcriptional activity is due to decreased phospho-MDM2 protein levels.

SIRT1 inhibition by miR-128 results in acetylation and nuclear translocation of FOXO3A. The literature suggests that in addition to deacetylating p53, SIRT1 also deacetylates and represses forkhead transcription factor, FOXO3A. ${ }^{28,29}$ Thus, downregulation of SIRT1 may result in increased acetylation of FOXO3A. Interestingly, overexpression of miR128 led to increased acetylated FOXO3A and total FOXO3A in HEK293T, HCT116 p53 + / + and HCT116 p53 - / - cells (Figures $4 a-c)$. There are also reports that FOXO3A is negatively regulated by $\mathrm{AKT}$, and in the absence of AKTmediated phosphorylation, FOXO3A translocates to nucleus. ${ }^{30}$ As we observed decrease in SIRT1 and pAKT levels, we next evaluated the effect of miR-128 on the phosphorylation of $\mathrm{FOXO} 3 \mathrm{~A}$ and its translocation to the nucleus in HEK293T cells. Overexpression of miR-128 significantly decreased the levels of phospho-FOXO3A (Figure 4d) and increased FOXO3A expression in the nuclear fractions (Figure 4e) in HEK293T cells as compared with that in controls. However, no significant increase in the transcriptional levels of FOXO3A was observed (Figure 4f).

miR-128 induces apoptosis in HEK293T cells in a p53-dependent and -independent manner. To confirm that miR-128 directly modulates p53, its levels were checked in the presence or absence of anti-miR-128 in HEK293T 
a

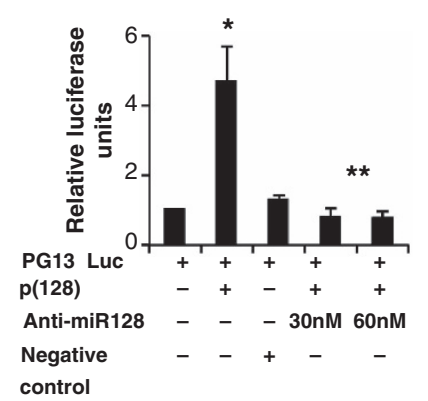

b
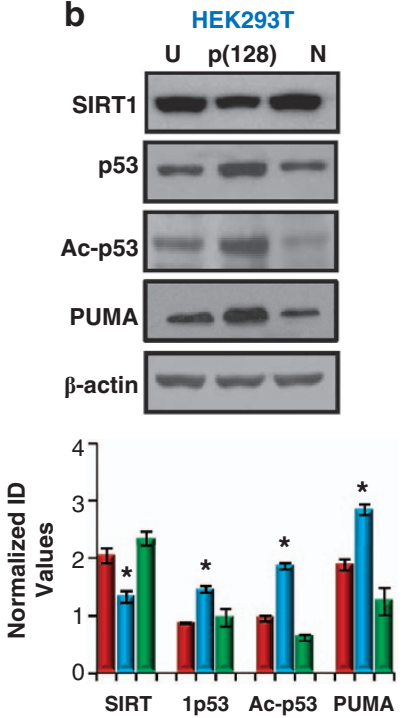
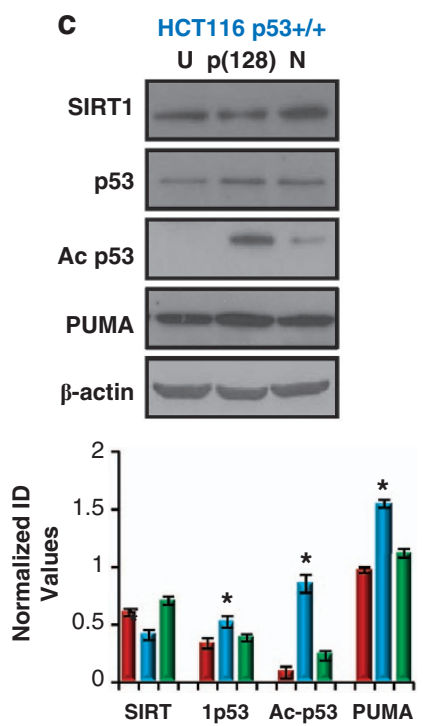
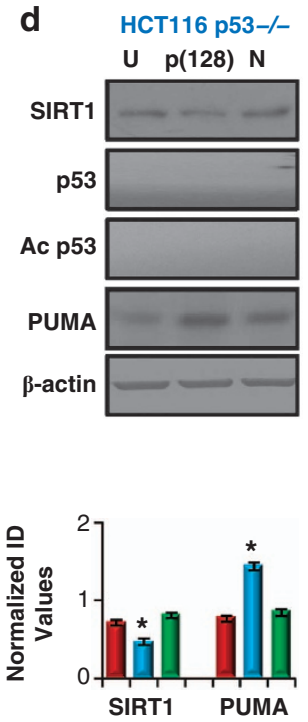
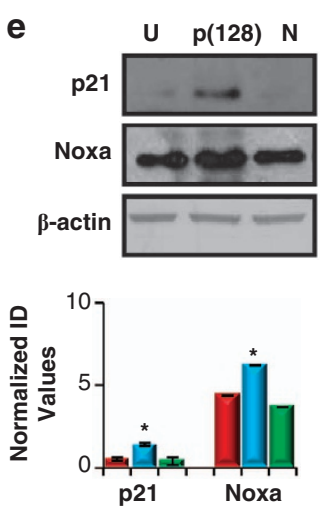
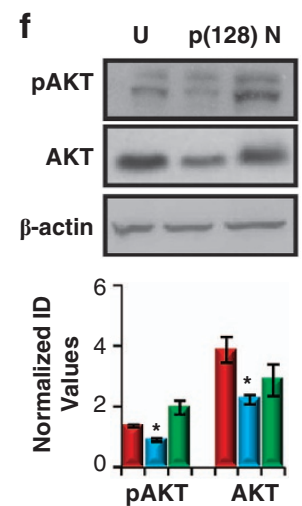

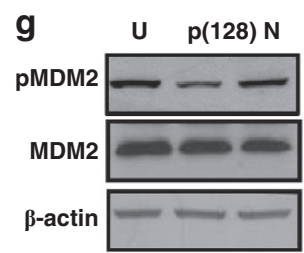

Untransfected

$\mathrm{p}(\mathbf{1 2 8 )}$

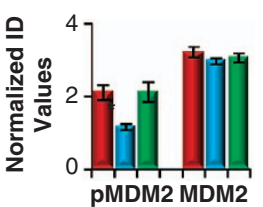

Figure 3 miR-128 regulates p53 and its transcriptional targets. (a) p53 transcriptional activity using a reporter gene assay in the presence of miR-128 and/or anti-miR-128. (b-d) Western blot analysis of SIRT1, p53, acetylated p53 and PUMA in HEK293T (b), HCT116 p53 + / + (c) and HCT116 p53 - / - (d) cells. (e-g) Western blot analysis of p21 and NOXA (e), total AKT and phospho-AKT (f), total MDM2 and phospho-MDM2 (g) after $24 \mathrm{~h}$ of transfection of $4 \mu \mathrm{g} p(128)$ and negative control in HEK293T cells. $\beta$-actin bands are the loading control. Lower panel shows the graph that represents the fold change in the protein level as compared with the untransfected HEK293T cells. $n=3 \pm$ S.D.; ${ }^{*} P<0.05$ versus negative control. $\mathrm{U}=$ untransfected, $\mathrm{p}(128)=$ HEK293T cells transfected with $4 \mu \mathrm{g} \mathrm{p}(128), N=$ negative control

cells. As expected, overexpression of miR-128 led to two-fold increase, whereas anti-miR treatment led to 1.85-fold decrease in p53 expression in HEK293T cells (Supplementary Figure S5a). To further elucidate the role of p53 in miR-128 induced apoptosis, annexin-V assay was done in the presence or absence of p53 siRNA in HEK293T cells. FACS analysis showed that treatment with scrambled siRNA failed to protect HEK293T cells from miR-128 induced-apoptosis, whereas inhibition of p53 by p53 siRNA partially rescued HEK293T cells from miR-128-induced apoptosis (Figure 5a), thereby suggesting that miR-128 induces apoptosis in a p53-dependent and -independent manner. Supplementary Figure S5b shows that the effect of miR-128 on p53 expression was reversed by p53 siRNA.

Simultaneously, apoptosis was also assessed in cells that harbor inactivating mutations in p53 (MDA-MB-231 (mutant p53 $\left.{ }^{\mathrm{R} 280 \mathrm{~K}}\right)$ ), in the presence or absence of miR-128 and/or anti-miR-128. In MDA-MB-231 cells, miR-128 induced apoptosis $(\sim 12.1 \pm 0.023 \%)$ whereas anti-miR-128 reduced apoptosis $(6.7 \pm 0.034 \%$, Figure $5 \mathrm{~b})$. You et al. ${ }^{31}$ demonstrated that FOXO3A causes p53-independent transcriptional activation of PUMA in response to cytokine/growth factor withdrawal, hence, we examined whether miR-128 activates PUMA in MDA-MB-231 cells also. Interestingly, miR-128 upregulated PUMA in miR-128-transfected MDA-MB-231 cells (Figure 5c). These findings further confirm that miR-128 induces apoptosis irrespective of p53 status in a p53-dependent and -independent manner via PUMA.

Although miR-128 might have additional targets, our experiments suggest that miR-128 indirectly regulates p53 through SIRT1. To confirm that SIRT1 regulates acetylation of p53, we transfected wild-type p53 expressing MCF7 and HCT116 p53+/+ cells with SIRT1 siRNA, and then measured p53, acetylated p53, total FOXO3A and acetylated FOXO3A. As expected, knockdown of SIRT1 increased acetylation of both p53 and FOXO3A in these cells (Figures 5d and e). 
a
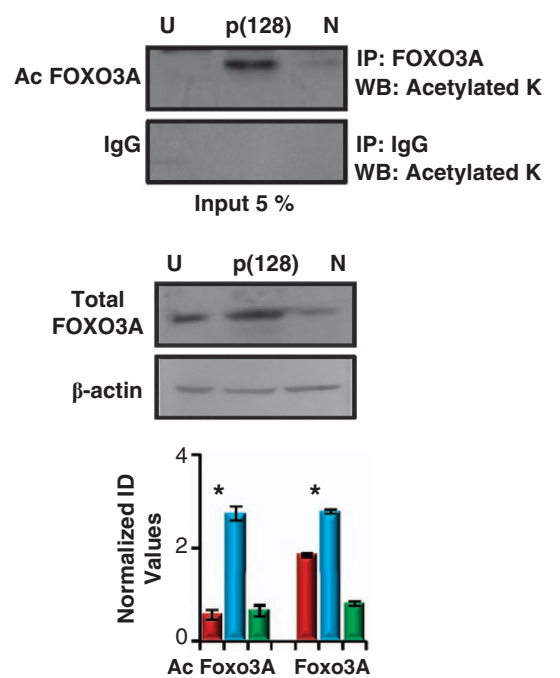

d
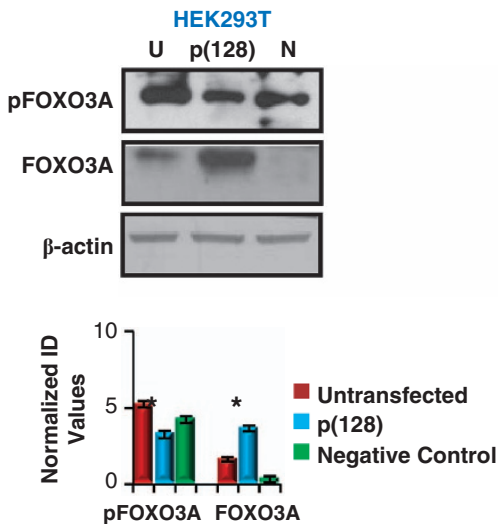

b
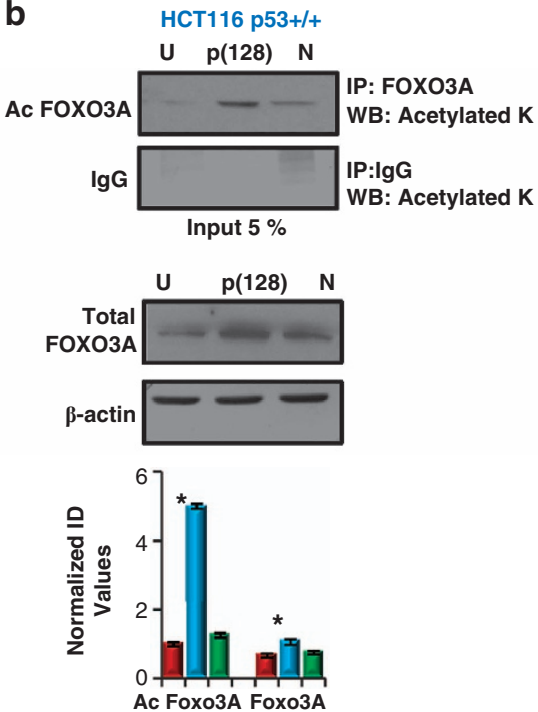

e

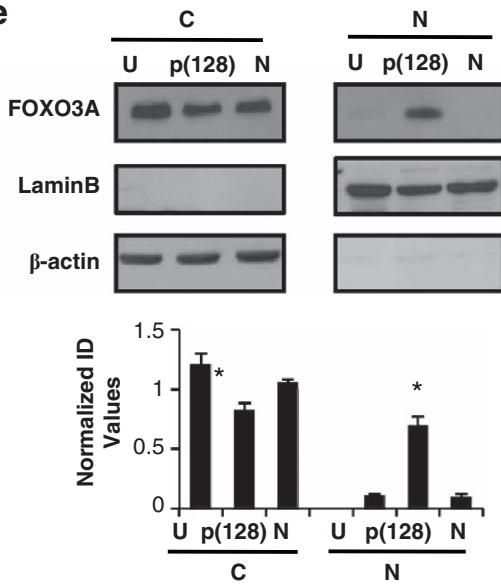

c
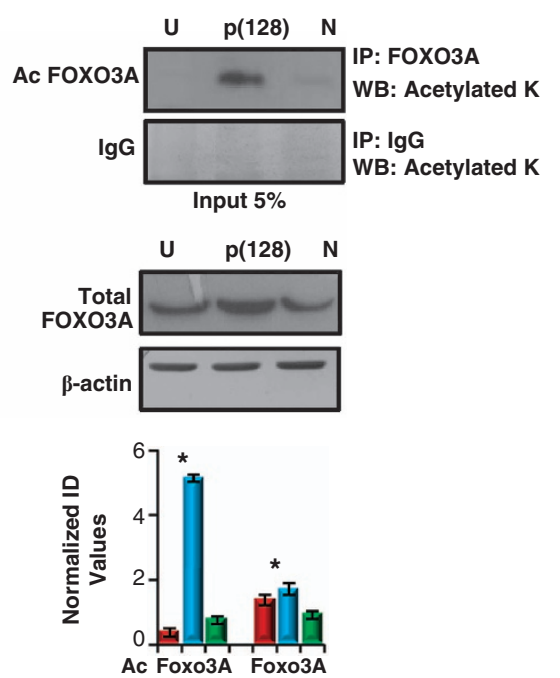

f

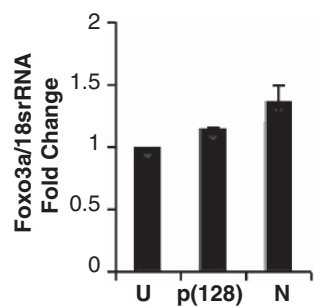

Figure 4 miR-128 regulates FOXO3A and promotes its translocation from the cytoplasm to the nucleus. (a-c) Whole-cell extracts $(500 \mu \mathrm{g})$ of untransfected and transfected HEK293T, HCT116 p53 + / + and HCT116 p53 - / - cells were immunoprecipitated with anti-FOXO3A, anti-IgG antibodies and analyzed by western blot analysis with anti-acetyl-lysine antibody. $5 \%$ input was used to detect the total FOXO3A and $\beta$-actin in all the cell lines. Bar diagram represents the changes in levels of acetylated FOXO3A as compared with negative control after normalization with $\beta$-actin. (d) Western blot analysis of total FOXO3A and pFOXO3A in HEK293T cells (e) Translocation of FOXO3A from cytoplasm to nucleus after the overexpression of miR-128 in HEK293T cells. Nuclear and cytoplasmic fractions were separated as described in the Materials and Methods. The purity of the nuclear fraction was determined by the expression of Lamin B (nuclear-specific protein). GAPDH was used as a loading control. C represents cytosolic fraction and $\mathrm{N}$ represents nuclear fraction. The upper panel is a representative blot and the lower one is the densitometric analysis of the same. $n=3 \pm$ S.D.; ${ }^{*} P<0.05$. (f) Real-time PCR analysis of FOXO3A in miR-128-transfected HEK293T cells. 18s rRNA was used for the normalization. $n=3 \pm$ S.D.; ${ }^{*} P<0.05 . \mathrm{U}=$ untransfected, $\mathrm{p}(128)=$ HEK293T cells transfected with $4 \mu \mathrm{g} \mathrm{p}(128), N=$ negative control

Standard chemotherapeutic agents etoposide and cisplatin have been known to activate p53 and we found activation of p53 by miR-128. Hence, we next explored the level of endogenous miR-128 with and without chemotherapeutic treatments for the wild-type p53-expressing cells (MCF7, NClH460, HCT116 p53 + / + ), p53 null cells (HCT116 p53 - /-) as well as mutant $\mathrm{p} 53^{\mathrm{R} 280 \mathrm{~K}}$ cells (MDA-MB-231), and evaluated in parallel, the level of SIRT1. Chemotherapeutic drugs caused slight-to-moderate increase in miR-128 levels only in p53 null cells (HCT116 p53-/-) and mutant p53 (MDA-MB-231, p53 R280K) cells, and decreased miR-128 levels in wild-type p53-expressing MCF7, $\mathrm{NCl}-\mathrm{H} 460$ and HCT116 p53 + I + cells (Figure 6a). Furthermore, chemotherapeutic drugs that induced miR-128, caused moderate increase in SIRT1 levels in p53 null cells (HCT116 p53-/-) and mutant p53 (MDA-MB-231, p53 ${ }^{\text {R280K }}$ ) cells, whereas they caused insignificant change in SIRT1 levels in wild-type p53-expressing MCF7, $\mathrm{NCl}-\mathrm{H} 460$ and HCT116 p53 $+/+$ cells (Figure 6b).

We simultaneously examined whether miR-128 would have any effect on the sensitivity of cells that have functional p53/ mutated p53 or are null for p53 towards chemotherapeutics. As expected, miR-128 augmented the cisplatin (33\% in MCF7 cells, $27.8 \%$ in HCT116 p53 $+/+$ cells and $21.45 \%$ in HCT116 p53 - / - cells ) as well as etoposide (44\% in MCF-7 cells, $32.25 \%$ in HCT116 p53 $+/+$ cells and $25.55 \%$ in HCT116 p53 - / - cells)-induced apoptosis as compared with their respective controls (Figures $7 \mathrm{a}-\mathrm{f}$ ). Apoptosis was also 
a

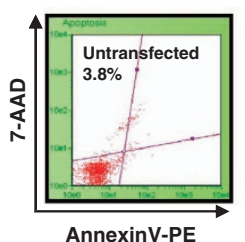

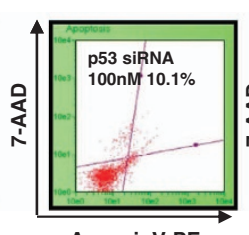

AnnexinV-PE

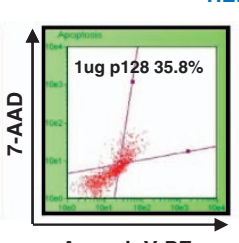

AnnexinV-PE

HEK293T

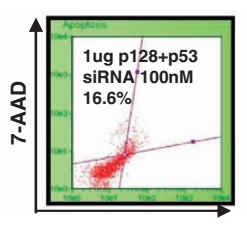

AnnexinV-PE

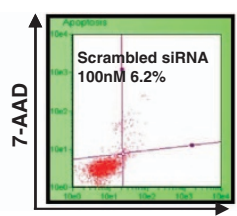

AnnexinV-PE

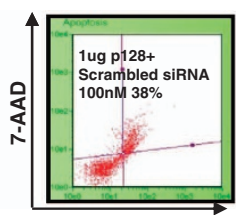

AnnexinV-PE

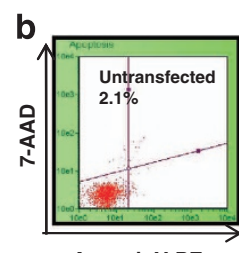

AnnexinV-PE

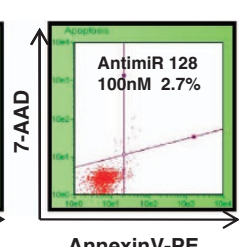

AnnexinV-PE

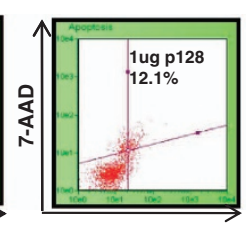

Annexin V-PE

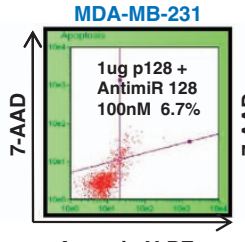

Annexin V-PE

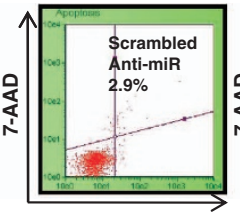

AnnexinV-PE

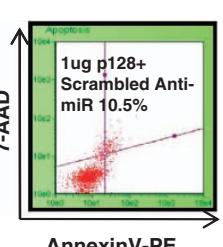

AnnexinV-PE
C

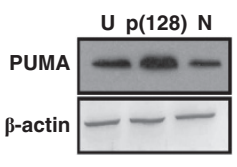

d

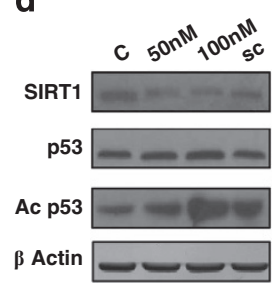

MCF7

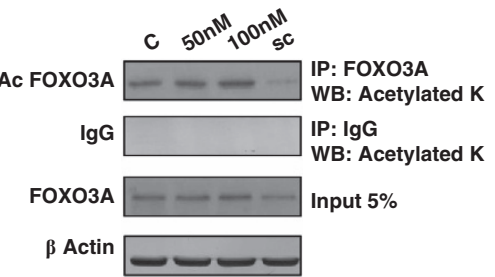

e

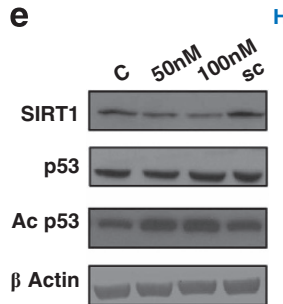

HCT116 p53+/+

Figure 5 miR-128 induces apoptosis in a p53-dependent and -independent manner. (a) Annexin V-staining of HEK293T cells transfected with p(128) and/or siRNA for p53. After $48 \mathrm{~h}$ of transfection, annexin $\mathrm{V}$ assay was performed as described in 'Materials and Methods'. \% here indicates the percentage of dead (early + late) cells. Representative of three independent experiments is shown here $(n=3 ; P<0.05)$. (b) Annexin V-staining shows that miR-128 induces apoptosis in p53-mutant MDA-MB-231 cells and apoptosis drops in the presence of anti-miR-128, confirming that miR-128-induced apoptosis is irrespective of p53 status. Representative of three independent experiments has been shown with similar results $(n=3, P<0.05)$. (c) Western blot analysis of PUMA after $24 \mathrm{~h}$ of transfection of $4 \mu \mathrm{g}$ p(128) in $\mathrm{p53}-\mathrm{mutant}$ MDA-MB-231 cells. $\beta$-actin bands are the loading control. Representative of three independent experiments is shown here. $U=u n t r a n s f e c t e d, p(128)=H E K 293 T$ cells transfected with $4 \mu \mathrm{g} \mathrm{p}(128), N=$ negative control. (d) SIRT1 regulates acetylation of p53 and FOXO3A. Left panel shows the western blot analysis of SIRT1, p53 and acetylated p53 in the presence of SIRT1 siRNA (at 50and $100 \mathrm{nM}$ dose) or scrambled siRNA in MCF7 cells and right panel shows the immunoprecipitation of whole-cell extracts (500 $\mu \mathrm{g}$ ) of untransfected and transfected MCF7 cells with anti-FOXO3A, anti-IgG antibodies followed by western blot analysis with anti-acetyl-lysine antibody. Five per cent input was used to detect the total FOXO3A and $\beta$-actin in all the cell lines. (e) Left panel shows the western blot analysis of SIRT1, p53 and acetylated p53 in the presence of SIRT1 siRNA (at 50 and $100 \mathrm{nM}$ dose) or scrambled siRNA in HCT116 p53 + / + cells and right panel shows that whole-cell extracts (500 $\mu \mathrm{g}$ ) of untransfected and transfected MCF7 cells were immunoprecipitated with anti-FOXO3A, anti-lgG antibodies and analyzed by western blot analysis with anti-acetyl-lysine antibody. Five per cent input was used to detect the total FOXO3A and $\beta$-actin in all the cell lines

assessed in cells in the presence or absence of anti-miR$128 \pm$ chemotherapeutic drugs. As shown in Figures $7 a-f$, the apoptosis augmented by miR-128 was remarkably reduced in the presence of anti-miR-128 treatment in all the cells, irrespective of p53 status. Similar results were also observed in HEK293T cells (which express functional p53 and have low endogenous miR-128 expression) as well as in Jurkat Cells (which lack functional p53 and have high endogenous miR-128 expression) as compared with their respective controls, thereby confirming that miR-128 induces apoptosis in a p53-dependent as well as -independent manner (Supplementary Figures 6a-c). Moreover, the proapoptotic effect of miR-128 was more pronounced in cells expressing wild-type p53 (because of the additive effect of $\mathrm{p53}$ and FOXO3A) than in cells expressing mutant p53 or no p53 (because of FOXO3A effect only).

miR-128-induced apoptosis depend upon PUMA-Bak axis. Previously, we had shown that miR-128 downregulates $\mathrm{Bax}$, upregulates Bak and induces apoptosis in HEK293T cells. ${ }^{20}$ In the current study, miR-128 not only induces apoptosis, but also upregulates PUMA in wild-type p53 HCT116 p53 + / + and p53 null HCT116 p53 - /- cells (Figures $3 c$ and $d$ ). Hence, we speculate that miR-128 induces apoptosis irrespective of p53 status in a p53dependent and -independent manner via PUMA. To clarify the role of p53, FOXO3A, Bak and PUMA in miR-128 induced apoptosis, we modulated their expression using respective siRNAs and examined apoptosis in HEK293T, HCT116 p53+/+ and HCT116 p53-/- cells (Table 2). Pre-treatment with FOXO3A siRNA partially reduced miR128-induced apoptosis, whereas pre-treatment with Bak and/or PUMA siRNAs significantly abolished miR-128induced apoptosis in all the cell lines, irrespective of p53 status. All these results suggest that miR-128 induces apoptosis in a p53-dependent and -independent manner via PUMA-Bak axis.

\section{Discussion}

p53 is the master factor at the center of a complex molecular network regulating a plethora of physiological responses in stressed conditions. Mutations in the TP53 gene are the most 

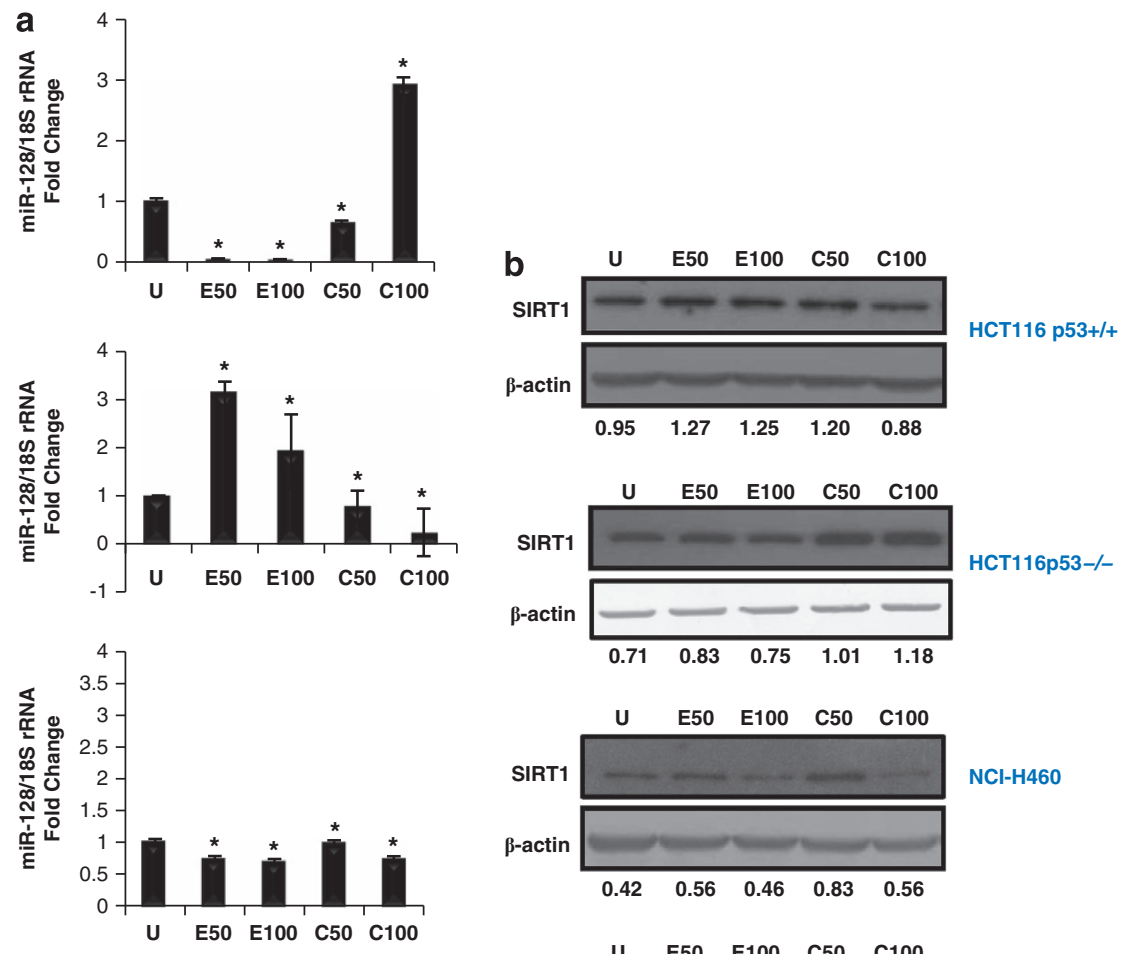

$\mathrm{NCl}-\mathrm{H} 460$
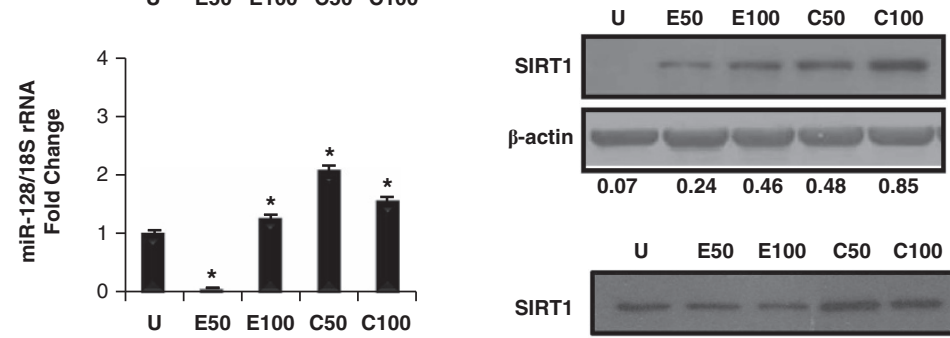

MDA-MB-23
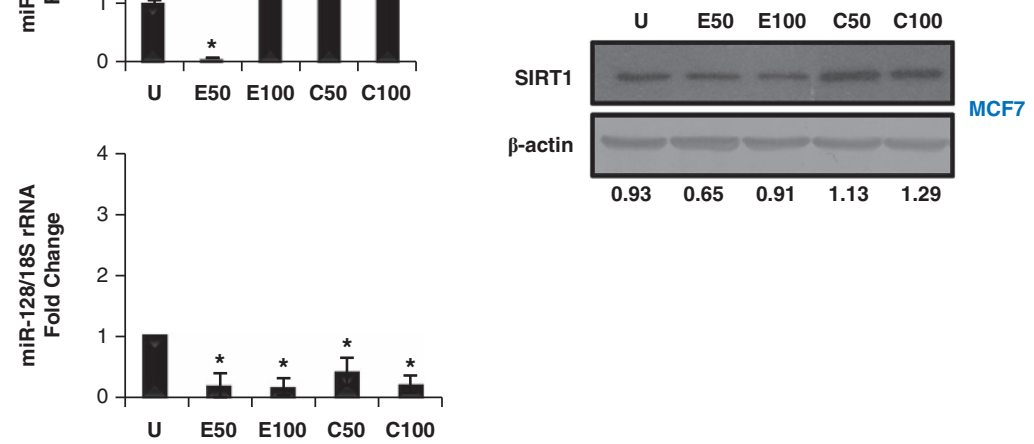

Figure 6 Relative expression of miR-128 and SIRT1 upon chemotherapeutic treatment. HCT116 p53 + / +, HCT116 p53 - / , NCI-H460, MDA-MB-231 and MCF7 cells were treated with etoposide and cisplatin and cells were assayed for the expression of mature miR-128 by Taqman assay (a) and SIRT1 by western blot analysis (b). Representative of three independent experiments has been shown with similar results $(n=3, P<0.05)$

frequent type of gene-specific alterations in human cancers that render them insensitive to cancer therapy. Additionally, in a number of cancers, the activity and function of p53 are frequently downregulated without mutations in the p53 gene itself. Since then, activation of p53 in tumor cells has been the prime focus of cancer drug discovery. ${ }^{32}$ Few miRNAs have been reported, like miR-34a, miR-29, miR-122 and miR-885$5 p$, that activate $p 53 .^{5-7,33}$ Previous report from our laboratory indicated that miR-128 upregulates p53 and induces apoptosis in HEK293T cells. ${ }^{20}$ These previous findings prompted us to investigate the role of p53 in miR-128-induced apoptosis.

We performed gene expression profiling in untransfected and miR-128-transfected HEK293T cells and interestingly, p53 turned out to be a key gene in one of the IPA networks. Validation of IPA network by real-time PCR showed significant increase in p53 and SIRT1 mRNA levels. The literature suggests that SIRT1 is a NAD ${ }^{+}$-dependent deacetylase, which has the ability to regulate a number of processes by deacetylating key proteins such as p53 (at K382), Foxo, Ku70 and provoke an inhibitory effect on apoptosis. ${ }^{24,34}$ On the contrary, downregulation of SIRT1 upregulates acetylated p53, causes transcriptional activation of p53 targets genes viz p21, NOXA and PUMA and thus induces apoptosis. ${ }^{5}$ In this study, we show that ectopic expression of miR-128 not only suppressed the levels of SIRT1 by binding to its $3-$ UTR, but also resulted in an increased acetylation of p53 (at K382) and 


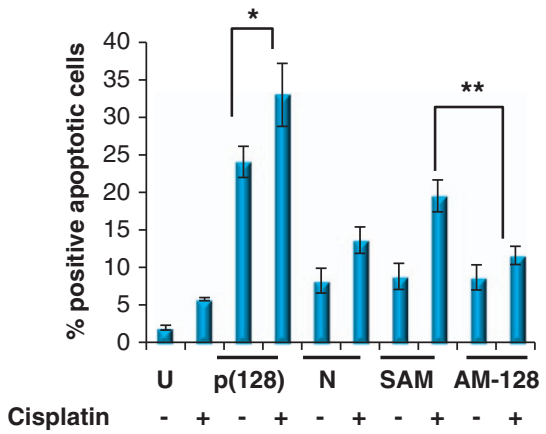

C
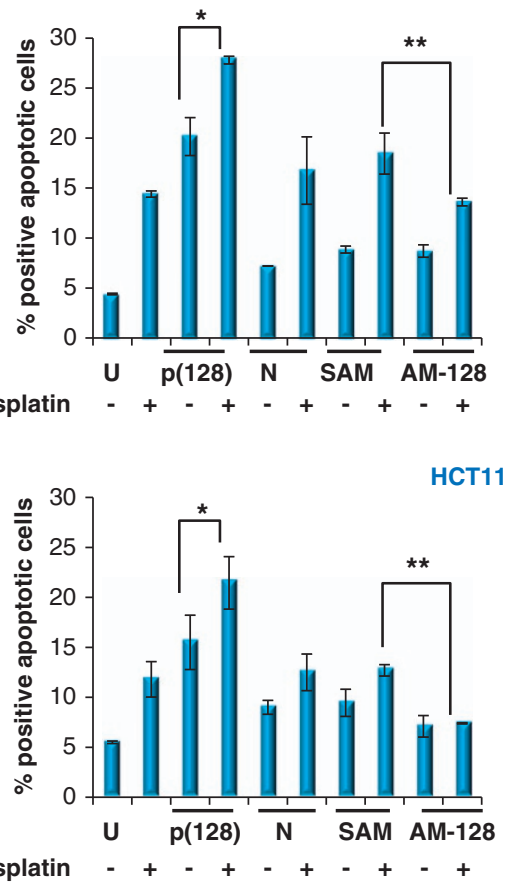

MCF7

b

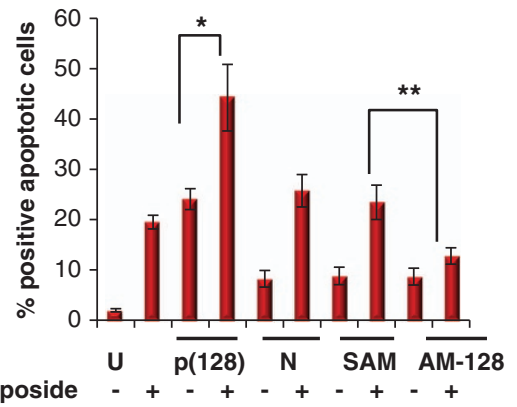

d

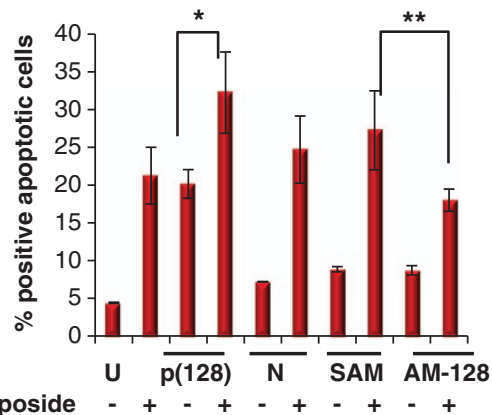

f

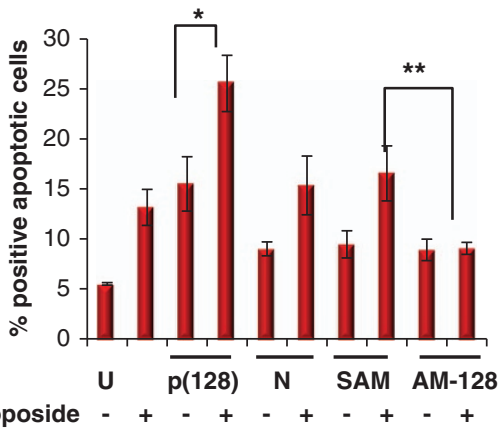

Figure 7 miR-128 induces apoptosis in a p53-dependent manner. (a,c and e) miR-128 augments antitumor effects of cisplatin. Annexin V-staining in MCF7 (a), HCT116 p53 $+/+$ (c) and HCT116 p53 - / - cells (e) transfected with p(128)/negative control/anti-miR-128/ scrambled anti-miR in the presence of cisplatin (CDDP, $100 \mu \mathrm{M})$. (b, d and f) Similar experiments were performed in the same cell lines in the presence of etoposide $(100 \mu \mathrm{M})$. All the cells were exposed to drugs after $6 \mathrm{~h}$ of transfection and $24 \mathrm{~h}$ post transfection, annexin V assay was performed as described in 'Materials and Methods' $\left(n=3\right.$, mean \pm S.D.; $\left.{ }^{*} P<0.05{ }^{* *} P<0.001\right)$. \% here indicates the percentage of dead (early + late) cells. Representative of three independent experiments has been shown with similar results

increased expression of p21, NOXA and PUMA (a BH3-only Bcl-2 family member), respectively. Consistent to our findings, Lain et al. ${ }^{35}$ reported that inhibition of SIRT1 by a specific inhibitor causes p53 hyperacetylation and increases p53dependent transcriptional activity. Increased SIRT1 expression (at mRNA level) after miR-128 overexpression that we had observed could be due to increased FOXO3A and/or p53. Nemoto et al. ${ }^{36}$ demonstrated that binding of p53 to two p53 binding sites in the SIRT1 gene promoter normally represses SIRT1 gene transcription and its removal by FOXO3A activates SIRT1 transcription. Taken together, our data proves that SIRT1 downregulation has a key role in miR128-induced apoptosis.

Transcription factor $\mathrm{FOXO} 3 \mathrm{~A}$ is also an important target protein of SIRT1 and interestingly, SIRT1-mediated deacetylation of the p53 parallels the effect of deacetylation of FOXO. ${ }^{28}$ Our study demonstrates that miR-128-mediated inhibition of SIRT1 not only acetylates p53, but also increases acetylated FOXO3A and leads to nuclear translocation of FOXO3A (by reduced phosphorylation of FOXO3A) (Figure 4c). Once inside the nucleus, FOXO3A induces the transcription of a variety of genes, including genes involved in DNA repair (GADD45 $\alpha$ ) and apoptosis (Bim and Fas ligand, PUMA). ${ }^{37,38}$ Consistent to these findings, we here observed increased GADD45 $\alpha$ (transcript levels) and PUMA (protein levels) after miR-128 overexpression. You et al. ${ }^{31}$ have shown that the nuclear-activated FOXO3A could bind the PUMA promoter regardless of p53 genotype, thereby demonstrating that FOXO3A can act directly on the PUMA promoter in a p53-independent manner. As in the present study we found 
increased nuclear accumulation of FOXO3A, increased PUMA expression and significant apoptosis in wild-type p53 (MCF-7) and mutant p53[MDA-MB-231 (mutant p53 ${ }^{\mathrm{R} 280 \mathrm{~K}}$ )] cells, one might speculate that miR-128 induces apoptosis in a p53-dependent and -independent manner via PUMA induction by $\mathrm{FOXO} 3 \mathrm{~A}$.

Upregulation of FOXO3A and its target PUMA in miR-128transfected HCT116 p53 $+/+$ and p53 null cells HCT116 p53 - / - further confirms that miR-128 induces apoptosis in p53-dependent and -independent manner.

Table 2 Results representing the Annexin assay after transfection of HEK293T, HCT116 p53 + / + and p53 - / - HCT116 with Bak, PUMA and Foxo3a siRNAs

\begin{tabular}{|c|c|c|c|}
\hline & HEK293T & $\begin{array}{l}\text { HCT116 } \\
\text { p53 + I+ }\end{array}$ & $\begin{array}{l}\text { HCT116 } \\
\text { p53-I- }\end{array}$ \\
\hline Untransfected & 5.5 & 6.9 & 9.4 \\
\hline $1 \mu \mathrm{g} \mathrm{p} 128$ & 42.8 & 27.4 & 20.1 \\
\hline 100 nM Bak siRNA & 6.7 & 9.6 & 9.9 \\
\hline $1 \mu \mathrm{g} \mathrm{p} 128+100 \mathrm{nM}$ Bak siRNA & 10.9 & 12.5 & 11.1 \\
\hline 100 nM PUMA SIRNA & 5.1 & 9.4 & 5.5 \\
\hline $1 \mu \mathrm{g}$ p $128+100 \mathrm{nM}$ PUMA siRNA & 12.6 & 13.7 & 11.5 \\
\hline 100 nM Foxo3a siRNA & 6.7 & 9.1 & 9.8 \\
\hline $1 \mu \mathrm{g}$ p128 + $100 \mathrm{nM}$ Foxo3a siRNA & 32.8 & 16 & 14 \\
\hline 100 nM scrambled siRNA & 3.5 & 8.6 & 9.4 \\
\hline $1 \mu \mathrm{g}$ p $128+100 \mathrm{nM}$ scrambled siRNA & 40.6 & 28.1 & 18 \\
\hline 100 nM Bak + PUMA siRNA & 5.5 & 8.5 & 8.9 \\
\hline $1 \mu \mathrm{g} p 128+100 \mathrm{nM}$ Bak + PUMA siRNA & 5.7 & 9.5 & 10 \\
\hline
\end{tabular}

Values represent the percentage of apoptosis.
Based on our current results and previous findings, ${ }^{20}$ we here propose a model of regulation of pro-apoptotic signaling pathway by miR-128 (Figure 8). Overexpression of miR-128 inhibits SIRT1 by directly binding to its $3^{\prime} U T R$. On one hand, downregulation of SIRT1 leads to increased p53 acetylation, increased p53 transcriptional activity and increased p21, NOXA and PUMA expression and on the other hand, it leads to increased acetylated FOXO3A. The literature suggests that apart from acetylation, FOXO3A proteins are also regulated by phosphorylation-dependent nuclear/cytoplasmic shuttling as a result of the activity of AKT. ${ }^{30}$ We show here that apart from downregulating SIRT1, miR-128 also decreases IGFBP5 RNA levels that might reduce the phosphorylation of $A K T$. The reduction of phospho-AKT, in turn, might reduce the phosphorylation of FOXO3A in miR-128-transfected cells and favour nuclear translocation of FOXO3A. Decreased phospho-AKT might also lead to decreased phospho-MDM2 and enhanced p53 stabilization. The literature suggests that the role of p53 is multifaceted and has transcription-dependent and -independent regulatory functions. In a transcription-independent manner, recent studies have demonstrated that a fraction of p53 translocates to mitochondria after an apoptotic stimulus. This might be happening in miR-128 induced apoptosis also, because we found increased p53 in mitochondrial fraction (data not shown) after miR-128 overexpression. Donna et al. ${ }^{39}$ have indicated that Bak rather than Bax is the principle extranuclear target of p53 and interaction of p53 with Bak would liberate Bak from its interaction with the

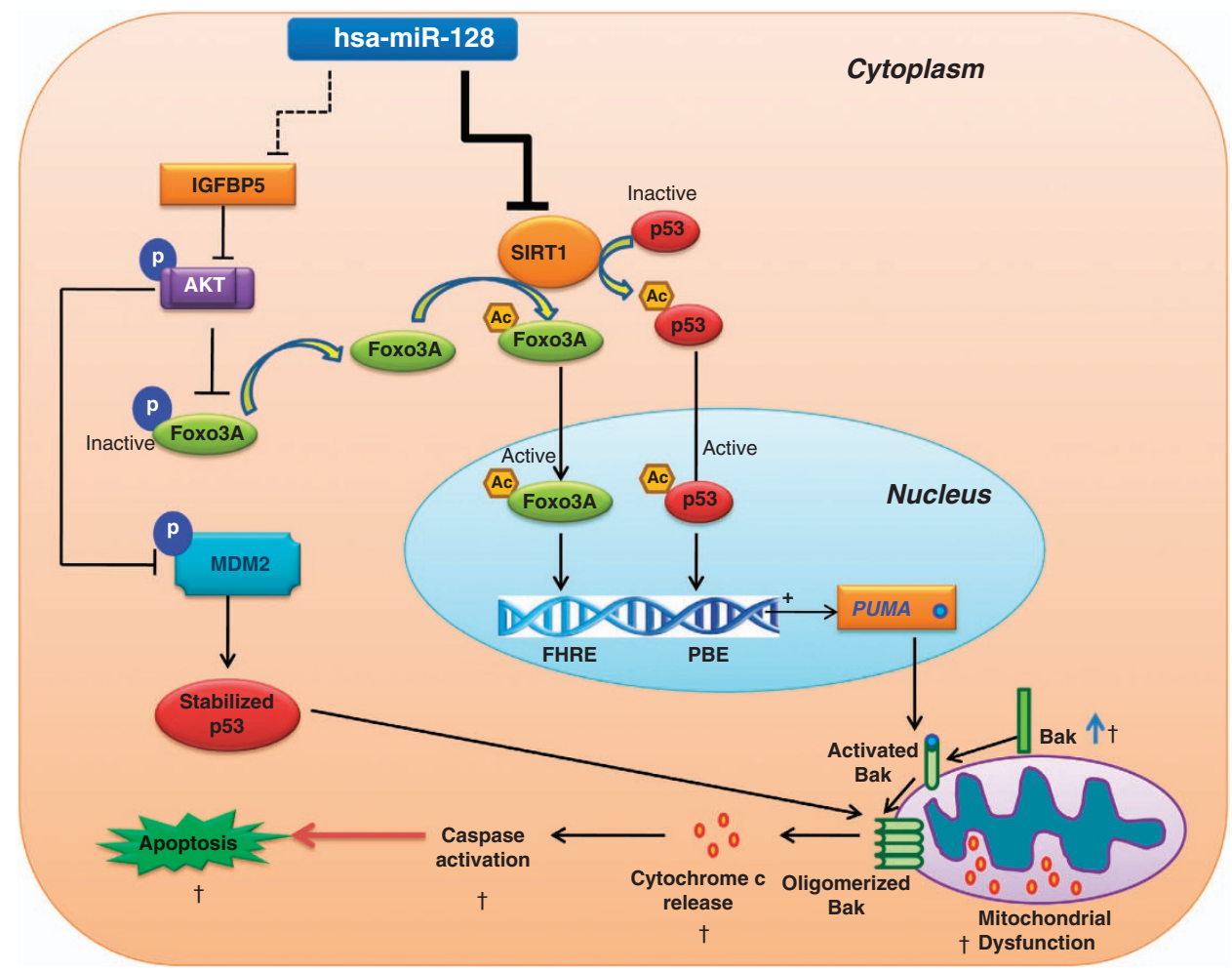

Figure 8 Proposed model of regulation of pro-apoptotic signaling pathway by miR-128. Our data shows that activation of p53, FOXO3A and PUMA and inhibition of SIRT1 and IGFBP5 may be responsible for miR-128-induced apoptosis in HEK293T cells. In a transcription-dependent and -independent manner, PUMA activates Bak, which may be the downstream molecule that is indirectly activated by miR-128 and causes induction of apoptosis. †indicates these have been shown in the previous study ${ }^{20}$ 
Mcl1. Disruption of Mcl1-Bak interaction would then unleash the mitochondrial outer membrane permeabilization (MOMP). Similarly, we speculate that in miR-128-overexpressed cells also, p53 might be interacting with mitochondrial Bak, thereby leading to increased Bak oliogmerization, increased mitochondrial dysfunction, cytochrome $c$ release and caspase activation, all of which might be leading to apoptosis as reported by us previously. ${ }^{20}$ In a transcription-dependent and -independent manner, PUMA must be interacting with Bak and inducing MOMP, leading to the release of cytochrome $c$ into cytosol and apoptosis. Defining these discrete functions and relationship to MOMP need further investigation.

SIRT1 is involved in a wide variety of cellular processes ranging from stress responses, aging and metabolism to cancer. ${ }^{40}$ SIRT1 is not only overexpressed in different cancers, ${ }^{41-44}$ but is also found to be overexpressed in drugresistant cancer cells. ${ }^{45}$ Luo et al. ${ }^{34}$ showed that by deacetylating p53, SIRT1 inhibits its action, viz, to arrest cell cycle and thereby increases the risk of cancer. On the contrary, Firestein et al. ${ }^{46}$ showed that induction of SIRT1 suppresses intestinal tumorigenesis and colon cancer growth. Considering the fact that SIRT1 is a multi-function protein and miR-128 downregulates SIRT1, our findings provide important evidence for the potential application of miR-128 in cancers as therapeutics.

Recent studies have shown that miRNAs are now entering into the p53 network. Treatment of cancers with wild-type p53 is promising, but for tumors with mutant p53, therapeutic approaches are still in infancy. Our results suggest that miR128 is a novel mitochondria-targeted miRNA that can be further evaluated as a chemotherapeutic agent for human cancers (with wild-type or mutant p53), as it induces apoptosis in a p53-dependent and -independent manner. Moreover, the fact that p53 and PUMA are frequently downregulated in plethora of cancers, and miR-128 upregulates both p53 and PUMA, it would be worthwhile to investigate whether the introduction of miR-128 into tumors can induce tumor regression. Future studies in this direction may provide conclusive answers.

\section{Materials and Methods}

Cell culture and transfection. HEK293T (human embryonic kidney), MCF-7 (human breast adenocarcinoma) and MDA-MB-231 (human breast adenocarcinoma, mutant p53 ${ }^{\mathrm{R} 280 \mathrm{~K}}$ ) cells were obtained from National Center for Cell Science, Pune, India, and maintained in DMEM media. HCT116 p53 $+/+$ and HCT116 p53 $-/$ - cells (human colon carcinoma cells) were kindly provided by Dr. Sanjeev Das, National Institute of Immunology Delhi, India. NCI-H460 (human large cell lung carcinoma) and Jurkat (T-cell leukemia) cells were maintained in RPMI medium. The media was supplemented with $10 \%$ (v/v) fetal calf serum, 100 units $/ \mathrm{ml}$ penicillin, $100 \mu \mathrm{g} / \mathrm{ml}$ streptomycin and $0.25 \mu \mathrm{g} / \mathrm{ml}$ amphotericin. The cells were grown at $37^{\circ} \mathrm{C}$ in a humidified atmosphere of $5 \% \mathrm{CO}_{2}$.

Overexpression of miR-128 in HEK293T cells was achieved by transfection in sixwell plates (for western blot, northern blot and Taqman assay) and 24-well plate (for luciferase assay and Annexin assay) using Lipofectamine 2000 (Invitrogen, Carlsbad, CA, USA) with $\mathrm{p}(128)$. In the case of $\mathrm{NCl}-\mathrm{H} 460$ cells, transfections were performed in the same manner using FuGENE HD (Roche, Mannheim, Germany). MCF-7, MDA-MB-231, HCT116 p53 + I+ and HCT116 p53- / - cells were transfected with plasmid and anti-miR-128 (Dharmacon, Danvers, Co, USA) using Lipofectamine 2000 (Invitrogen) according to the manufacturer's protocol. Jurkat cells were transfected via electroporation using the Amaxa system (program X001;
Lonza, Basel, Switzerland), nucleofector solution V with anti-miR-128 or scrambled anti-miR (SAM). ON-TARGETplus SMARTpool siRNAs for human SIRT1, FOXO3A, Bak1, PUMA (BBC3), p53 siRNA and Non-targeting siRNA SMARTpool (D-001810-01-05) were purchased from Dharmacon and transfected into the cells for $48 \mathrm{~h}$ using Lipofectamine 2000. Etoposide and cisplatin (CDDP) were used at a concentration of $100 \mu \mathrm{M}$.

Plasmid constructs. miR-128 was cloned in pSilencer 4.1 vector (Ambion Inc., Austin, TX, USA) and designated as $p(128)$ as described. ${ }^{20}$ The negative control is the pSilencer 4.1 vector that expresses a hairpin siRNA with limited homology to any known sequence in human (Ambion Inc.). $3^{\prime}$ UTR reporter construct of SIRT1 was purchased from Addgene (Addgene Inc., Cambridge, MA, USA). ${ }^{5}$ Site-directed mutagenesis was performed to construct the mutant SIRT1 3'UTR reporter construct using Quick-Change Site-Directed Mutagenesis kit (Stratagene, La Jolla, CA, USA). Mutation was done by deletion of the seed sequence of the predicted miR-128-binding site using the primers as described in Supplementary Table S3. The resulting plasmids were sequenced to ensure accuracy.

RNA extraction and cRNA preparation. Total RNA (untransfected HEK293T, transfected HEK293T with $p(128)$ ) was extracted using Trizol reagent (Invitrogen) and subjected to purification using RNeasy MinElute cleanup kit (Qiagen, Valencia, CA, USA), by essentially following the manufacturer's instructions. RNA samples were run on $1 \%$ agarose gel for testing their integrity. Quantification of RNA was done on a nanodrop spectrophotometer by measuring absorbance at 260 and $280 \mathrm{~nm}$ (ND 1000). Illumina TotalPrep RNA Amplification Kit (Ambion Inc.) was used to prepare biotinylated cRNA, following the manufacturer's instruction. Briefly, $500 \mathrm{ng}$ of total RNA was reverse transcribed with an oligo dT primer using ArrayScript enzyme (Ambion Inc., Austin, TX, USA). The cDNA synthesized was column-purified and was subjected to in vitro transcription to produce biotinylated cRNA. The cRNA (amplified RNA) was further column-purified.

Illumina microarray and data analysis. For genome-wide expression profiling, HEK293T cells were transfected in triplicate with $p(128)$ in a six-well plate. Microarray experiment was performed in three biological replicates of untransfected HEK293T cells and HEK293T cells transfected with $4 \mu \mathrm{g}$ of $p(128)$. Total RNA (untransfected and transfected samples) was extracted after $24 \mathrm{~h}$ of transfection using Trizol reagent (Invitrogen) as per manufacturer's instructions. Briefly, $1.5 \mu \mathrm{g}$ of labeled amplified RNA was hybridized to Illumina Genome-Wide Expression BeadChips (Human ref. 6 v.3.0, Illumina) representing $\sim 38275$ human transcripts at $58^{\circ} \mathrm{C}$ overnight. The array was washed and blocked, and the hybridized beads were stained with Streptavidin Cy3 (Sigma, St Louis, MO, USA). The chips were scanned using Illumina scanner iScan (Illumina). The data was analyzed using Analysis module of Illumina Bead Studio3 Software. The data was average-normalized and FDR calculation was done using illumine custom test. The genes that crossed the threshold of detection $P$ value $\leqslant 0.01$ among all the samples and differential $P$ value $\leqslant 0.05$ among the test samples were considered to be the differentially expressed genes. The dataset of genes obtained in the microarray has been deposited in NCBI's Gene Expression Omnibus (GEO accession number GSE31297) (http://www.ncbi.nlm. nih.gov/geo/query/acc.cgi?acc=GSE31297).

Ingenuity Pathway Analysis (IPA). To explore the possible biological interactions as well as specific pathways, datasets representing genes with altered expression profile derived from microarray analyses were imported into the Ingenuity Pathway Analysis Tool. Ingenuity Pathway Knowledge Base (IPKB) is the basis of IPA, which is derived from known functions and interactions of published genes. Thus, the IPA Tool allows the identification of biological networks, global functions and functional pathways of a particular dataset. A 1.5 -fold change was set to identify genes whose expression was significantly differentially regulated. These genes, called the focus genes, were then networked with the other genes that were dependent on their interaction. The program also gives the significance value of the genes, the other interacting genes and how the products of the genes directly or indirectly act on each other, including those not involved in the microarray analysis. A network is a graphical representation of the molecular relationships between these genes where genes or gene products are represented as nodes, and the biological relationship between two nodes is represented as an edge (line). The networks created are ranked depending on the number of significantly expressed genes. This program also lists molecular and cellular functions that were most significant. 
Northern blotting. Total RNA was extracted using Trizol reagent (Invitrogen), as per the manufacturer's instructions. Forty microgram of RNA was resolved on $15 \%$ urea-polyacrylamide gel and transferred to Hybond $N+$ membrane (GE Healthcare Ltd, Little Chalfont, UK) using semidry apparatus (BioRad, Hercules, CA, USA). The blot was probed with a RNA probe made by miRVana probe construction kit (Ambion). The blot was scanned in the phosphorimager (Spinco Laboratory, Chennai, India) and the normalization of the result was done by probing it for U6 expression.

Western blotting. We performed western blotting as described in our earlier study, ${ }^{20}$ using untransfected and transfected cells (with $p(128)$ and negative control). Primary antibodies anti-p53, anti-SIRT1, anti-PUMA, anti-NOXA, antiphospho-FOXO3A, anti-AKT, anti-phospho-AKT, anti-phospho-MDM2 were from Santa Cruz Biotechnology Inc. (Santa Cruz, CA, USA). Anti FOXO3A, antiacetylated lysine antibody, anti-p21 and anti-acetyl-p53 were from Cell Signaling Technology (Danvers, MA, USA). Anti MDM2 was purchased from Abcam (Cambridge, MA, USA). The secondary antibodies were anti-mouse ALP-linked or anti-rabbit HRP-linked and blots were developed using NBT-BCIP (Sigma) or ECL (Kodak; Sigma). Equal loading of protein was confirmed using $\beta$-actin antibody. Integrated Density values were then calculated using Alphalmager 3400 (Alpha InnoTech Corporation, San Leandro, CA, USA). These values were then normalized to $\beta$-actin. All experiments were repeated at least three times; representative results are presented.

Luciferase assay. HEK293T cells were seeded into 24-well plates 1 day before transfection. Cotransfection of $200 \mathrm{ng}$ of firefly luciferase containing $3^{\prime} \mathrm{UTR}$ SIRT1 and/or $200 \mathrm{ng}$ p-Silencer 4.1 vector expressing miR-128 p(128) or negative control along with $30 \mathrm{ng} \mathrm{pRL}-\mathrm{CMV}$ plasmid that expressed Renilla luciferase (Promega, Madison, WI, USA) using Lipofectamine 2000 (Invitrogen). AntimiR-128 (30 or $60 \mathrm{nM}$; Dharmacon) was also used wherever indicated. For mutant cotranfection, $200 \mathrm{ng}$ of SIRT1 3'UTR reporter (wild type or mutated), $200 \mathrm{ng}$ of $\mathrm{p}(128)$ (miR-128) or negative control and $30 \mathrm{ng}$ of $\mathrm{pRL}-\mathrm{CMV}$ were transiently transfected in HEK293T cells. After $24 \mathrm{~h}$ of transfection, luciferase activity was measured using the Dual-luciferase assay kit as described by the manufacturer (Promega). Firefly luciferase activity was normalized to Renilla luciferase activity. These experiments were performed in triplicates.

For p53 transcriptional activity, luciferase reporter gene assay was performed. In brief, HEK293T cells were cotransfected with PG13-Luc (reporter construct that contains an array of 13 repeats for p53-binding sites upstream of the luciferase gene). Renilla-expressing plasmid pRL-CMV was cotransfected to normalize the variations. Total amount of plasmid DNA was kept constant by the addition of pcDNA3.1plasmid. Cell lysates were prepared using Passive Lysis Buffer (Promega) $48 \mathrm{~h}$ after transfection. The absolute values of firefly luminescence were normalized to those of Renilla and the ratios were presented as mean \pm standard deviation (S.D.).

Preparation of nuclear and cytosolic extracts. Nuclear and cytosolic extracts were prepared using NE-PER Nuclear and Cytoplasmic Extraction kit (Pierce, Thermo Fisher Scientific, Waltham, MA, USA) according to the manufacturer's instructions. Briefly, untransfected and transfected cells (with $p(128)$ and negative control) were pelleted down and $100 \mu$ l of ice-cold CER I was added to the cell pellet. The samples were vortexed vigorously for $15 \mathrm{~s}$ and incubated on ice for $10 \mathrm{~min}$. Then, $5.5 \mu \mathrm{l}$ of ice-cold CER II was added and the samples were vortexed for $5 \mathrm{~s}$. The samples were incubated on ice for $1 \mathrm{~min}$ and vortexed vigorously for $5 \mathrm{~s}$. The samples were centrifuged for $5 \mathrm{~min}$ at $\sim 16000 \times g$ and the supernatant (cytoplasmic extract) was immediately transferred to a clean prechilled tube. The insoluble (pellet) fractions, which contained nuclei, were suspended in $50 \mu \mathrm{l}$ ice-cold NER and vortexed for $15 \mathrm{~s}$. The samples were placed on ice and vortexed continuously for $15 \mathrm{~s}$ every $10 \mathrm{~min}$, for a total of $50 \mathrm{~min}$. The samples were centrifuged at $\sim 16000 \times \mathrm{g}$ in a microcentrifuge for $10 \mathrm{~min}$ and the supernatant (nuclear fraction) was collected. Protein content in all fractions was determined using BCA method and the extracts were stored at $-80^{\circ} \mathrm{C}$.

Apoptosis assay. HEK293T, MCF-7, MDA-MB-231 cells, HCT116 p53+/+, HCT116 p53 - / - and Jurkat cells were seeded in a 24-well plate and transfected with $p(128)$ or negative control and/or anti-miR-128, scrambled anti-miR or p53 siRNA or FOXO3A siRNA or Bak siRNA or PUMA siRNA, wherever needed, for $24 \mathrm{~h}$. Apoptosis was assessed after $24 \mathrm{~h}$ by using the Guava Nexin kit and the Guava PCA system (Guava Technologies, Hayward, CA, USA). The Nexin assay was performed according to the manufacturer's protocol. Annexin-PE fluorescence was analyzed by cytosoft software (Guava Technologies). A minimum of 2000 events were counted. ${ }^{20}$

Real-time PCR. Real-time PCR was performed as described in our earlier study, ${ }^{20}$ using untransfected and transfected cells (with $p(128)$ and negative control). Analysis was done using the Pfaffl's method. ${ }^{47}$ Primer sequences for TP53, SIRT1, RXRA, IGFBP5, COL5A1, NOTCH1, TGFB1 GADD45 $\alpha$, FOXO3A and 18srRNA are listed in Supplementary Table S3.

Taqman microRNA assay. Total RNA (untransfected, transfected with $\mathrm{p}(128)$ and negative control) was extracted using Trizol reagent (Invitrogen) and reverse transcribed with M-MuLV reverse transcriptase (Fermentas, Glen Burnie, $M D$, USA) according to the manufacturer's protocol. TaqMan microRNA assay (Applied Biosystems, Foster City, CA, USA) was performed as described in our earlier study. ${ }^{20}$

Immunofluorescence analysis. Cells were seeded on coverslips in a sixwell plate (Tarsons, New Delhi, India) at $1.6 \times 10^{5}-2 \times 10^{5}$ per well for $24 \mathrm{~h}$ prior to transfection. Transfection was done with $p(128)$ using lipofectamine 2000 , as described by the manufacturer. After $24 \mathrm{~h}$ of transfection, the cells were rinsed with PBS and fixed with ice-cold acetone: methanol mix $(1: 1)$ for $10 \mathrm{~min}$ at $-20^{\circ} \mathrm{C}$. They were rinsed again and permeabilized with $0.5 \%$ Triton X-100 in PBS for $15 \mathrm{~min}$ at room temperature. Subsequently, they were washed with PBS and consequently blocked for $45 \mathrm{~min}$ in $1 \%$ bovine serum albumin in PBS at room temperature, washed with PBS, and incubated with anti-SIRT1 antibody $(1: 50$, Santa Cruz Biotechnology) for $2 \mathrm{~h}$ at room temperature. Then, cells were washed with PBS and incubated with the secondary antibody Alexa 594-conjugated goat anti-mouse IgG (A11005; Molecular Probes, Eugene, OR, USA; Invitrogen) for $45 \mathrm{~min}$ at room temperature. Finally, cells were washed with PBS and stained with DAPI $(0.5 \mu \mathrm{g} / \mathrm{ml})$ for $10 \mathrm{~min}$. Fluorescent images were captured through an inverted microscope Nikon ECLIPSE Ti (Nikon Corporation, Tokyo, Japan) at room temperature with a $60 \times$ NA 1.4, using a DS-Qi1MC camera equipped with NIS Element AR 3.0 software. To calculate the staining intensity of SIRT1 in the nucleus, mean pixel intensities were obtained for the nuclear region ( $\sim 10$ cells) using NIS Element AR 3.0 software and these were averaged to generate a mean value.

Co-immunoprecipitation assay. Untransfected and transfected cells were lysed with cell lysis buffer ( $50 \mathrm{mM}$ Tris buffer, $\mathrm{pH} 7.4$, containing $150 \mathrm{mM}$ $\mathrm{NaCl}, 5 \mathrm{mM}$ EDTA, $1 \% \mathrm{NP} 40)$ with freshly added protease inhibitors $(1 \mu \mathrm{g} / \mathrm{ml}$ aprotinin, $1 \mu \mathrm{g} / \mathrm{ml}$ leupeptin, $1 \mu \mathrm{g} / \mathrm{ml}$ pepstatin and $1 \mathrm{mM}$ PMSF) and phosphatase inhibitors $(20 \mathrm{mM} \mathrm{NaF}$ and $1 \mathrm{mM}$ orthovanadate). Lysates were immunoprecipitated with $2 \mu \mathrm{g}$ anti-FKHRL-1 (FOXO3A) antibody for overnight at $4^{\circ} \mathrm{C}$ and incubated with protein $A$ sepharose beads (Sigma) for $2 \mathrm{~h}$ at $4^{\circ} \mathrm{C}$. The immunocomplexes were then washed five times with cell lysis buffer and probed by western blotting. Primary antibodies used for immunoblotting were antiacetylated lysine, anti- $\beta$ actin and total FOXO3A.

Statistical analysis. Results are given as mean of three independent experiments \pm S.D. An independent Student's two-tailed, paired $t$-test was performed using replicate values. Values of $P<0.05$ were considered statistically significant.

\section{Conflict of Interest}

The authors declare no conflict of interest.

Acknowledgements. This work was supported by Grant BSC0123 from the Council of Scientific and Industrial Research (CSIR). YKA was supported with a fellowship from CSIR. We thank Professor Samir K Brahmachari for project conceptualization. We also acknowledge Anita Goel, Ravindresh Chhabra, Vikas Yadav, Shruti Chowdhari, Anirban Kar and Gunjan for their help. We also acknowledge Dr. Sanjeev Das, National Institute of Immunology, Delhi, India, for providing HCT116 p53 + I+ and HCT116 p53 - / - cells.

1. Vousden KH, Prives C. Blinded by the light: the growing complexity of p53. Cell 2009; 137: 413-431.

2. Levine AJ, Hu W, Feng Z. The P53 pathway: what questions remain to be explored? Cell Death Differ 2006; 13: 1027-1036. 
3. Hu W, Chan CS, Wu R, Zhang C, Sun Y, Song JS et al. Negative regulation of tumo suppressor p53 by microRNA miR-504. Mol Cell 2010; 38: 689-699.

4. Le MT, Teh C, Shyh-Chang N, Xie H, Zhou B, Korzh V et al. MicroRNA-125b is a novel negative regulator of p53. Genes Dev 2009; 23: 862-876.

5. Yamakuchi M, Ferlito M, Lowenstein CJ. miR-34a repression of SIRT1 regulates apoptosis. Proc Natl Acad Sci USA 2008; 105: 13421-13426.

6. Fornari F, Gramantieri L, Giovannini C, Veronese A, Ferracin M, Sabbioni S et al. MiR-122/ cyclin $\mathrm{G} 1$ interaction modulates p53 activity and affects doxorubicin sensitivity of human hepatocarcinoma cells. Cancer Res 2009; 69: 5761-5767.

7. Park SY, Lee JH, Ha M, Nam JW, Kim VN. miR-29 miRNAs activate p53 by targeting p85 alpha and CDC42. Nat Struct Mol Biol 2009; 16: 23-29.

8. Bartel DP. MicroRNAs: target recognition and regulatory functions. Cell 2009; 136: 215-233.

9. Karp X, Ambros V. Developmental biology. Encountering microRNAs in cell fate signaling Science 2005; 310: 1288-1289.

10. Chen CZ, Li L, Lodish HF, Bartel DP. MicroRNAs modulate hematopoietic lineage differentiation. Science 2004; 303: 83-86

11. Lynam-Lennon N, Maher SG, Reynolds JV. The roles of microRNA in cancer and apoptosis. Biol Rev Camb Philos Soc 2009; 84: 55-71.

12. Slack FJ, Weidhaas JB. MicroRNAs as a potential magic bullet in cancer. Future Oncol 2006; 2: 73-82.

13. Cimmino A, Calin GA, Fabbri M, lorio MV, Ferracin M, Shimizu M et al. miR-15 and miR-16 induce apoptosis by targeting BCL2. Proc Natl Acad Sci USA 2005; 102: 13944-13949.

14. He L, Thomson JM, Hemann MT, Hernando-Monge E, Mu D, Goodson S et al. A microRNA polycistron as a potential human oncogene. Nature 2005; 435: 828-833.

15. Evangelisti C, Florian MC, Massimi I, Dominici C, Giannini G, Galardi S et al. MiR-128 up-regulation inhibits Reelin and DCX expression and reduces neuroblastoma cell motility and invasiveness. FASEB J 2009; 23: 4276-4287.

16. Zhang Y, Chao T, Li R, Liu W, Chen Y, Yan X et al. MicroRNA-128 inhibits glioma cells proliferation by targeting transcription factor E2F3a. J Mol Med (Berl) 2009; 87: 43-51.

17. Khan AP, Poisson LM, Bhat VB, Fermin D, Zhao R, Kalyana-Sundaram S et al. Quantitative proteomic profiling of prostate cancer reveals a role for miR-128 in prostate cancer. Mol Cell Proteomics 2010; 9: 298-312.

18. Weiss GJ, Bemis LT, Nakajima E, Sugita M, Birks DK, Robinson WA et al. EGFR regulation by microRNA in lung cancer: correlation with clinical response and survival to gefitinib and EGFR expression in cell lines. Ann Oncol 2008; 19: 1053-1059.

19. Kotani A, Ha D, Schotte D, den Boer ML, Armstrong SA, Lodish HF. A novel mutation in the miR-128b gene reduces miRNA processing and leads to glucocorticoid resistance of MLL-AF4 acute lymphocytic leukemia cells. Cell Cycle 2010; 9: 1037-1042.

20. Adlakha YK, Saini N. MicroRNA-128 downregulates Bax and induces apoptosis in human embryonic kidney cells. Cell Mol Life Sci 2011; 68: 1415-1428.

21. Lewis BP, Shih IH, Jones-Rhoades MW, Bartel DP, Burge CB. Prediction of mammalian microRNA targets. Cell 2003; 115: 787-798.

22. John B, Enright AJ, Aravin A, Tuschl T, Sander C, Marks DS. Human microRNA targets PLOS Biol 2004; 2: e363.

23. Jin Q, Yan T, Ge X, Sun C, Shi X, Zhai Q. Cytoplasm-localized SIRT1 enhances apoptosis. J Cell Physiol 2007; 213: 88-97.

24. Vaziri H, Dessain SK, Ng Eaton E, Imai SI, Frye RA, Pandita TK et al. hSIR2(SIRT1) functions as an NAD-dependent p53 deacetylase. Cell 2001; 107: 149-159.

25. Dai C, Gu W. p53 post-translational modification: deregulated in tumorigenesis. Trends $\mathrm{Mol}$ Med 2010; 16: 528-536.

26. Vilborg A, Wilhelm MT, Wiman KG. Regulation of tumor suppressor p53 at the RNA level. J Mol Med (Berl) 2010; 88: 645-652.

27. Lu J, Kovach JS, Johnson F, Chiang J, Hodes R, Lonser R et al. Inhibition of serine/ threonine phosphatase PP2A enhances cancer chemotherapy by blocking DNA damage induced defense mechanisms. Proc Natl Acad Sci USA 2009; 106: 11697-11702.

28. Brunet A, Sweeney LB, Sturgill JF, Chua KF, Greer PL, Lin Y et al. Stress-dependent regulation of FOXO transcription factors by the SIRT1 deacetylase. Science 2004; 303 2011-2015.
29. Acharya MR, Sparreboom A, Venitz J, Figg WD. Rational development of histone deacetylase inhibitors as anticancer agents: a review. Mol Pharmacol 2005; 68: 917-932.

30. Brunet A, Bonni A, Zigmond MJ, Lin MZ, Juo P, Hu LS et al. Akt promotes cell survival by phosphorylating and inhibiting a Forkhead transcription factor. Cell 1999; 96 : 857-868.

31. You $H$, Pellegrini M, Tsuchihara K, Yamamoto $K$, Hacker G, Erlacher $M$ et al. FOXO3a-dependent regulation of Puma in response to cytokine/growth factor withdrawal. J Exp Med 2006; 203: 1657-1663.

32. Feng Z, Zhang C, Wu R, Hu W. Tumor suppressor p53 meets microRNAs. J Mol Cell Biol 2011; 3: 44-50.

33. Afanasyeva EA, Mestdagh $P$, Kumps $C$, Vandesompele J, Ehemann V, Theissen $\mathrm{J}$ et al. MicroRNA miR-885-5p targets CDK2 and MCM5, activates p53 and inhibits proliferation and survival. Cell Death Differ 2011; 18: 974-984.

34. Luo J, Nikolaev AY, Imai S, Chen D, Su F, Shiloh A et al. Negative control of p53 by Sir2alpha promotes cell survival under stress. Cell 2001; 107: 137-148.

35. Lain S, Hollick JJ, Campbell J, Staples OD, Higgins M, Aoubala M et al. Discovery, in vivo activity, and mechanism of action of a small-molecule p53 activator. Cancer Cell 2008; 13 : 454-463.

36. Nemoto S, Fergusson MM, Finkel T. Nutrient availability regulates SIRT1 through a forkhead-dependent pathway. Science 2004; 306: 2105-2108

37. Birkenkamp KU, Coffer PJ. Regulation of cell survival and proliferation by the FOXO (Forkhead box, class 0 ) subfamily of Forkhead transcription factors. Biochem Soc Trans 2003; 31: 292-297.

38. Van Der Heide LP, Hoekman MF, Smidt MP. The ins and outs of FoxO shuttling: mechanisms of FoxO translocation and transcriptional regulation. Biochem J 2004; 380: 297-309

39. Leu JI, Dumont P, Hafey M, Murphy ME, George DL. Mitochondrial p53 activates Bak and causes disruption of a Bak-Mcl1 complex. Nat Cell Biol 2004; 6: 443-450.

40. Kwon HS, Ott M. The ups and downs of SIRT1. Trends Biochem Sci 2008; 33: 517-525

41. Yeung F, Hoberg JE, Ramsey CS, Keller MD, Jones DR, Frye RA et al. Modulation of NF-kappaB-dependent transcription and cell survival by the SIRT1 deacetylase. EMBO J 2004; 23: 2369-2380

42. Hida Y, Kubo Y, Murao K, Arase S. Strong expression of a longevity-related protein, SIRT1, in Bowen's disease. Arch Dermatol Res 2007; 299: 103-106.

43. Huffman DM, Grizzle WE, Bamman MM, Kim JS, Eltoum IA, Elgavish A et al. SIRT1 is significantly elevated in mouse and human prostate cancer. Cancer Res 2007; 67: 6612-6618.

44. Kuzmichev A, Margueron R, Vaquero A, Preissner TS, Scher M, Kirmizis A et al. Composition and histone substrates of polycomb repressive group complexes change during cellular differentiation. Proc Natl Acad Sci USA 2005; 102: 1859-1864.

45. Chu F, Chou PM, Zheng X, Mirkin BL, Rebbaa A. Control of multidrug resistance gene mdr1 and cancer resistance to chemotherapy by the longevity gene sirt1. Cancer Res 2005; 65: 10183-10187.

46. Firestein R, Blander G, Michan S, Oberdoerffer P, Ogino S, Campbell J et al. The SIRT1 deacetylase suppresses intestinal tumorigenesis and colon cancer growth. PLOS One 2008; 3: e2020.

47. Pfaffl MW. A new mathematical model for relative quantification in real-time RT-PCR. Nucleic Acids Res 2001; 29: e45.

(c) (i) ()) $\ominus$ Cell Death and Disease is an open-access journal published by Nature Publishing Group. This work is licensed under a Creative Commons Attribution-NonCommercialNoDerivs 3.0 Unported License. To view a copy of this license, visit http://creativecommons.org/licenses/by-nc-nd/3.0/ 